\title{
Aflasafe SN01 is the First Biocontrol Product Approved for Aflatoxin Mitigation in Two Nations, Senegal and The Gambia
}

\author{
A. L. Senghor, ${ }^{1}$ A. Ortega-Beltran, ${ }^{2}$ J. Atehnkeng, ${ }^{2}$ P. Jarju, ${ }^{3}$ P. J. Cotty, ${ }^{4,5}$ and R. Bandyopadhyay ${ }^{2, \dagger}$ \\ ${ }^{1}$ La Direction de Protection Végétaux, BP20054 Dakar, Senegal \\ ${ }^{2}$ International Institute of Tropical Agriculture (IITA), Ibadan, Nigeria \\ ${ }^{3}$ National Food Security, Processing and Marketing Corporation, Denton Bridge, Banjul, The Gambia \\ ${ }^{4}$ United States Department of Agriculture, Agricultural Research Service, Tucson, AZ 85719, U.S.A. \\ ${ }^{5}$ College of Food Science and Engineering, Ocean University of China, Qingdao, 266003, China
}

\begin{abstract}
Aflatoxin contamination is caused by Aspergillus flavus and closely related fungi. In The Gambia, aflatoxin contamination of groundnut and maize, two staple and economically important crops, is common. Groundnut and maize consumers are chronically exposed to aflatoxins, sometimes at alarming levels, and this has severe consequences on their health and productivity. Aflatoxin contamination also impedes commercialization in local and international premium markets. In neighboring Senegal, an aflatoxin biocontrol product containing four atoxigenic isolates of A. flavus, Aflasafe SN01, has been registered and is approved for commercial use in groundnut and maize. We detected that the four genotypes composing Aflasafe SN01 are also native to The Gambia. The bio-

smallholder farmers in The Gambia. Treated crops contained up to $100 \%$ less aflatoxins than untreated crops. A large portion of the crops could have been commercialized in premium markets due to the low aflatoxin content (in many cases no detectable aflatoxins), both at harvest and after storage. Substantial aflatoxin reductions were also achieved when commercially produced groundnut received treatment. Here we report for the first time the use and effectiveness of an aflatoxin biocontrol product registered for use in two nations. With the current scale-out and -up efforts of Aflasafe SN01, a large number of farmers, consumers, and traders in The Gambia and Senegal will obtain health, income, and trade benefits.
\end{abstract} control product was tested during two years in 129 maize and groundnut fields and compared with corresponding untreated fields cropped by
Keywords: aflatoxin biocontrol, atoxigenic isolates, postharvest benefits
In tropical and subtropical areas, aflatoxins contaminate several staple crops, including maize and groundnut, during crop production

Current address of A. L. Senghor: IITA, 7 Avenue Bourguiba BP 48, Dakar RP, Senegal

Current address of J. Atehnkeng: IITA, Bukavu, DR Congo

${ }^{\dagger}$ Corresponding author: R. Bandyopadhyay; r.bandyopadhyay@cgiar.org

Funding: Funding support of the United States Department of Agriculture, Foreign Agricultural Service, the Bill \& Melinda Gates Foundation (OPP1007117, OPP1133356), and the CGIAR Research Program on Agriculture for Nutrition and Health (A4NH) by CGIAR Trust Fund contributors (https://www.cgiar.org/research/) is gratefully acknowledged.

The use of trade, firm, or corporation names in these methods is for the information and convenience of the reader. Such use does not constitute an official endorsement or approval by the USDA Agricultural Research Service, of any product or service to the exclusion of others that may be suitable. In addition, USDA-ARS makes no warranties as to the merchantability or fitness of the methodologies described on these pages for any particular purpose, or any other warranties expressed or implied. These methodologies provide a guide and do not replace published work. USDA-ARS is not liable for any damages resulting from the use or misuse of these methodologies.

The authors receive no direct financial benefit from the manufacturing and marketing of aflatoxin biocontrol products mentioned in this article. The Aflasafe name is a Trademark of the International Institute of Tropical Agriculture (IITA). In the past, IITA manufactured Aflasafe for use in Nigeria, Senegal, Kenya, Burkina Faso, The Gambia, and Ghana. Manufacturing and distribution responsibilities have been licensed to private or public sector entities in a few African nations. ITTA charges a small licensing fee to manufacturers for use of the Aflasafe name and cost associated with technology transfer and technical backstopping. L. A. Senghor, A. OrtegaBeltran, J. Atehnkeng, and R. Bandyopadhyay are employed by IITA.

Accepted for publication 15 December 2020.

Copyright $\odot 2021$ The Author(s). This is an open access article distributed under the CC BY 4.0 International license. and postproduction stages (Udomkun et al. 2017a). Aflatoxins are highly toxic and carcinogenic mycotoxins produced by certain members of Aspergillus section Flavi (Amaike and Keller 2011; Frisvad et al. 2019). Aflatoxin-producing fungi infect crops before, during, and after harvest and can produce aflatoxins during all these stages if conducive conditions for toxin formation occur (Kachapulula et al. 2017a; Seetha et al. 2017). Aflatoxin contamination results in significant health, developmental, trade, and economic problems in the affected regions/nations (Nishimwe et al. 2019; Wu 2015). The aflatoxin problem is frequent in West African nations. In The Gambia, only a few studies report aflatoxin in crops/foods (Hudson et al. 1992, Jallow et al. 2019; Xu et al. 2017) and none at a nationwide household scale. However, in The Gambia, high human aflatoxin exposure is common (Groopman et al. 1992; Kirk et al. 2006; Kuniholm et al. 2008; Wild et al. 1992), including among children and pregnant mothers (Castelino et al. 2014; Turner et al. 2000, 2003, 2007; Zarba et al. 1992). Exposure at an early life stage may impede normal child development and proper cognitive functions (JECFA 2018). Aflatoxin management strategies to reduce contamination throughout the crop value chains and reduce human exposure are urgently needed for implementation across The Gambia.

The Gambia Standards Bureau has set up the standard GAMS CAC/RCP 55 - 2004, a code of good practice for the prevention and reduction of aflatoxin contamination in groundnut (https:// tgsb.gm/published-standards). This standard is based on maximum aflatoxin limits set by the Codex Alimentairus Commission (GAMX Codex Standard 200-1915), 15 parts per billion (ppb), for groundnut to be processed (PACA 2019). However, monitoring and enforcing aflatoxin regulations in The Gambia, and across sub-Saharan Africa (SSA), is challenged by several technical, policy, and institutional barriers (Matumba et al. 2017; PACA 2019). Groundnut consignments from The Gambia to the European Union, even as less lucrative feed, are frequently notified for rejection by the Rapid Alert System for Food and Feed for having unacceptable aflatoxin levels (RASFF 2019). Improved capacity to manage aflatoxins would significantly increase export potential of groundnut even for the more lucrative human food market. 
The major aflatoxin producer across the globe is A. flavus. This species can be subdivided into two distinct morphotypes, the $\mathrm{L}$ and the $\mathrm{S}$, based on morphological, physiological, and genetic criteria (Cotty 1989; Probst et al. 2014). Both morphotypes can produce B aflatoxins. However, in the $\mathrm{L}$ morphotype, genotypes unable to produce aflatoxins (i.e., atoxigenic) are common and contain genetic defects in one or more of the genes necessary for aflatoxin biosynthesis (Chang et al. 2012; Donner et al. 2010). The S morphotype consistently produces high aflatoxin levels (Cotty et al. 2008). In West Africa, fungi belonging to the B-aflatoxin-producing S morphotype of A. flavus have not been detected. In contrast, a group of fungi relatively common across the subregion resembles the $S$ morphotype but produces both B and G aflatoxins (Atehnkeng et al. 2008; Cotty and Cardwell 1999; Diedhiou et al. 2011; Ezekiel et al. 2014). That group was named as unknown taxon $\mathrm{S}_{\mathrm{BG}}$ and may be any of the recently described species A. aflatoxiformans, A. austwickii, A. cerealis, A. minisclerotigenes, or unnamed taxa (Frisvad et al. 2019; Probst et al. 2014; Singh and Cotty 2019). In this paper, as in previous ones (Agbetiameh et al. 2019; Ezekiel et al. 2019), we use the term ' $\mathrm{S}_{\mathrm{BG}}$ strains' for all fungi with $\mathrm{S}$ morphotype and producing both $\mathrm{B}$ and $\mathrm{G}$ aflatoxins. Each of the fungi mentioned above can be subdivided into vegetative compatibility groups (VCGs) (Bayman and Cotty 1991, 1993; Leslie 1993). Members of a VCG are more closely related among themselves than to members of other VCGs and there is little genetic variation within a VCG (Grubisha and Cotty 2010, 2015; Ortega-Beltran et al. 2016).

Many practices can reduce crop aflatoxin content at different stages of the crop value chain (Aoun et al. 2020; Mahuku et al. 2019; Seetha et al. 2017; Waliyar et al. 2015; Xu et al. 2017). However, when each practice is used in isolation, aflatoxin contamination often occurs above safe, permissible levels, particularly in tropical and subtropical regions (Ayalew et al. 2017). An effective, practical technology that provides protection to crops across the value chain is the use of atoxigenic isolates of A. flavus as biocontrol agents (Cotty 2006; Dorner 2004; Mehl et al. 2012). Atoxigenic isolates applied in the field, at the right stage of crop production, creates a founding population (Ortega-Beltran et al. 2020) that displace aflatoxin producers, and thus less aflatoxins accumulate in treated crops. The technology was developed by the United States Department of Agriculture - Agricultural Research Service (USDA-ARS) for use in cottonseed production in the U.S. (Cotty et al. 2007). It has been adapted for use in maize, groundnut, pistachio, almond, and figs produced in the U.S. (Dorner 2009; Doster et al. 2014; Ortega-Beltran et al. 2019). Production of highly lucrative crops in aflatoxin-prone areas of the U.S. could not be possible without the protection provided by an aflatoxin management system centered on biocontrol (Cotty et al. 2007; Doster et al. 2014; Ortega-Beltran and Bandyopadhyay 2019).

The aflatoxin biocontrol technology has been adapted and improved for use in SSA by the International Institute of Tropical Agriculture (IITA) and USDA-ARS in collaboration with several national institutions and international partners (Bandyopadhyay et al. 2016; Schreurs et al. 2019). Several atoxigenic biocontrol products under the trade name Aflasafe have been developed. They are now available for commercial use in Nigeria, Kenya, Senegal, Ghana, Burkina Faso, Tanzania, Zambia, Malawi, and Mozambique (Moral et al. 2020). Each product contains as active ingredient four atoxigenic isolates of A. flavus native to the target country. The atoxigenic isolates belong to atoxigenic African A. flavus VCGs (AAVs), and some products contain AAVs present in one or more countries (Agbetiameh et al. 2019; Moral et al. 2020). When applied at the right crop stage and at the recommended dose, biocontrol-treated crops typically contain $>80 \%$ less (sometimes $100 \%$ ) aflatoxins compared with neighboring, untreated crops, and most treated crops can meet the most rigid aflatoxin regulatory standards (Agbetiameh et al. 2020; Bandyopadhyay et al. 2019; Ezekiel et al. 2019; Senghor et al. 2020).

Native and wide distribution nature of the active ingredients are important considerations in the selection of isolates composing each biocontrol product targeted for any country (Bandyopadhyay et al. 2016; Mehl et al. 2012). Aflasafe SN01, the product developed for use in Senegal, is registered by the Comité Sahélien des Pesticides (CSP) of the Comité Inter-Etate pour la Lutte contre la Sécheresse au Sahel (CILSS) for use in maize and groundnut (Bandyopadhyay et al. 2016; Senghor et al. 2020). The four atoxigenic AAVs composing the product are distributed across major agricultural areas of Senegal. Thus, it is highly likely that those genotypes could co-occur in the neighboring country, The Gambia. If the four Aflasafe SN01 AAVs occur in The Gambia, it would be plausible to pursue the use of the product in that country because the genotypes would be adapted to its environmental and cropping conditions. Superior adaptation may increase the chances of success in reducing aflatoxin contamination under field conditions (Mehl et al. 2012). Noteworthy, registration of a biopesticide with CSP/CILSS allows the use of such product in all other CILSS countries, including The Gambia. However, finding Aflasafe SN01 AAVs in the target intervention area and testing the product across The Gambia are necessary to ensure that the active ingredient AAVs will be effective (Bandyopadhyay et al. 2016).

The objectives of this study were to determine i) aflatoxin prevalence in groundnut across The Gambia, ii) compositions of Aspergillus section Flavi communities in The Gambia, iii) presence/absence of Aflasafe SN01 AAVs in those communities, and iv) effectiveness of Aflasafe SN01 in reducing aflatoxin in groundnut and maize. This study laid the foundation for using the same biocontrol product (Aflasafe SN01) commercially to manage aflatoxins in The Gambia in addition to Senegal.

\section{Materials and Methods}

Sample collection and preparation. Groundnut samples were collected during January 2013 across seven regions of The Gambia: Central River North (CRN), Central River South (CRS), Lower River (LR), North Bank (NB), Upper River North (URN), Upper River South (URS), and West Coast (WC) (Fig. 1 ). Those are the major groundnut-producing regions of the country. Four villages were visited per region, and five groundnut samples (unshelled pods, $\sim 1 \mathrm{~kg}$ ) were collected from farmer stores (140 samples, Table 1). Groundnut in The Gambia is harvested during October to November. By the time of collection, the samples had remained in the farmers' store for 2 to 3 months. The samples were transported by road to Dakar, Senegal, and the quarantine authority of La Direction de Protection Végétaux (DPV) of Senegal provided a phytosanitary permit to send the samples to IITA's Pathology and Mycotoxin Unit in Ibadan, Nigeria, for laboratory analyses. Nigeria Agricultural Quarantine Service (NAQS) provided an import permit. Pods were shelled and kernels (approx. $750 \mathrm{~g}$ ) were milled using a laboratory blender (Waring Commercial, Springfield, MO) for $30 \mathrm{~s}$ in a 250 -ml stainless steel blending jar (MC-2) and stored at $4{ }^{\circ} \mathrm{C}$ before aflatoxin and microbial analyses. The blending jar was thoroughly washed with $80 \%$ ethanol after milling each sample to prevent cross-contamination of aflatoxins and microorganisms among samples.

Aflatoxin analysis, baseline study, and effectiveness trials. For each milled groundnut sample (approx. $750 \mathrm{~g}$ ), a $20 \mathrm{~g}$ subsample was randomly taken. The subsamples were combined with $100 \mathrm{ml}$ $80 \%$ methanol (Dorner and Cole 1993). The resulting suspensions were shaken on a Roto-Shake Genie (Scientific Industries, Bohemia, NY) for $30 \mathrm{~min}$ at $400 \mathrm{rpm}$. Then, suspensions were filtered through Whatman No. 1 filter paper (Whatman Intl. Ltd., Maidstone, England). Aflatoxins from the filtrates were then extracted as previously described (Agbetiameh et al. 2018; Atehnkeng et al. 2008). Aflatoxins were quantified using a scanning densitometer (CAMAG TLC Scanner 3) and quantification software (winCATS 1.4.2, Camag, AG, Muttenz, Switzerland) as described previously (Cotty and Cardwell 1999; Probst and Cotty 2012). The limit of detection was $1 \mathrm{ppb}$, while the recovery percentage was $>85 \%$.

Fungal isolation, identification, and densities. Compositions of fungal communities associated with groundnut in The Gambia were determined by identifying Aspergillus section Flavi fungi and 
characterizing them into their corresponding species (Table 2). For this, the dilution plate technique on modified Rose Bengal agar was used (Cotty 1994), and a total of 12 Aspergillus section Flavi isolates were recovered from each sample as previously described (Agbetiameh et al. 2018; Atehnkeng et al. 2008). Aspergillus section Flavi fungi were identified based on their colony characteristics, spore ornamentation, and aflatoxin-production profile (Cotty 1989; Cotty and Cardwell 1999; Klich and Pitt 1988). Isolates were saved as agar plugs ( $3 \mathrm{~mm}$ diameter) of sporulating cultures in $4 \mathrm{ml}$ vials containing $2 \mathrm{ml}$ sterile distilled water and maintained at room temperature until used in other studies. Population density of Aspergillus section Flavi fungi was calculated as colony-forming units (CFU) per $\mathrm{g}$ of sample as per methods described previously (Agbetiameh et al. 2018; Atehnkeng et al. 2008).

Aflatoxin-producing potential of the recovered fungi. Each of the 1,608 Aspergillus section Flavi recovered isolates was evaluated for their ability to produce aflatoxins (Table 3) in sterile, dead autoclaved maize kernels (Agbetiameh et al. 2018;
Probst and Cotty 2012). Aflatoxins were extracted from maize fermentations and quantified as described above, except that $70 \%$ methanol was used instead of $80 \%$. Isolates that did not produce aflatoxins on maize fermentations were classified as atoxigenic.

Vegetative compatibility analyses. All the recovered A. flavus $\mathrm{L}$ morphotype isolates were subjected to vegetative compatibility analyses (VCA) to determine whether they belong to any of the four AAVs to which the isolates composing Aflasafe SN01 belong (Table 4). Nitrate-nonutilizing (nit) mutants were generated as previously described (Atehnkeng et al. 2014, 2016). Tester pairs of AAVs in Aflasafe SN01 were previously generated (Senghor et al. 2020). VCA and assignment of isolates into one of the four AAVs composing the biocontrol product were conducted as previously described (Atehnkeng et al. 2014; Grubisha and Cotty 2010).

The biocontrol product and its manufacturing. Aflasafe SN01 was produced in IITA-Ibadan (Nigeria) in the Aflasafe

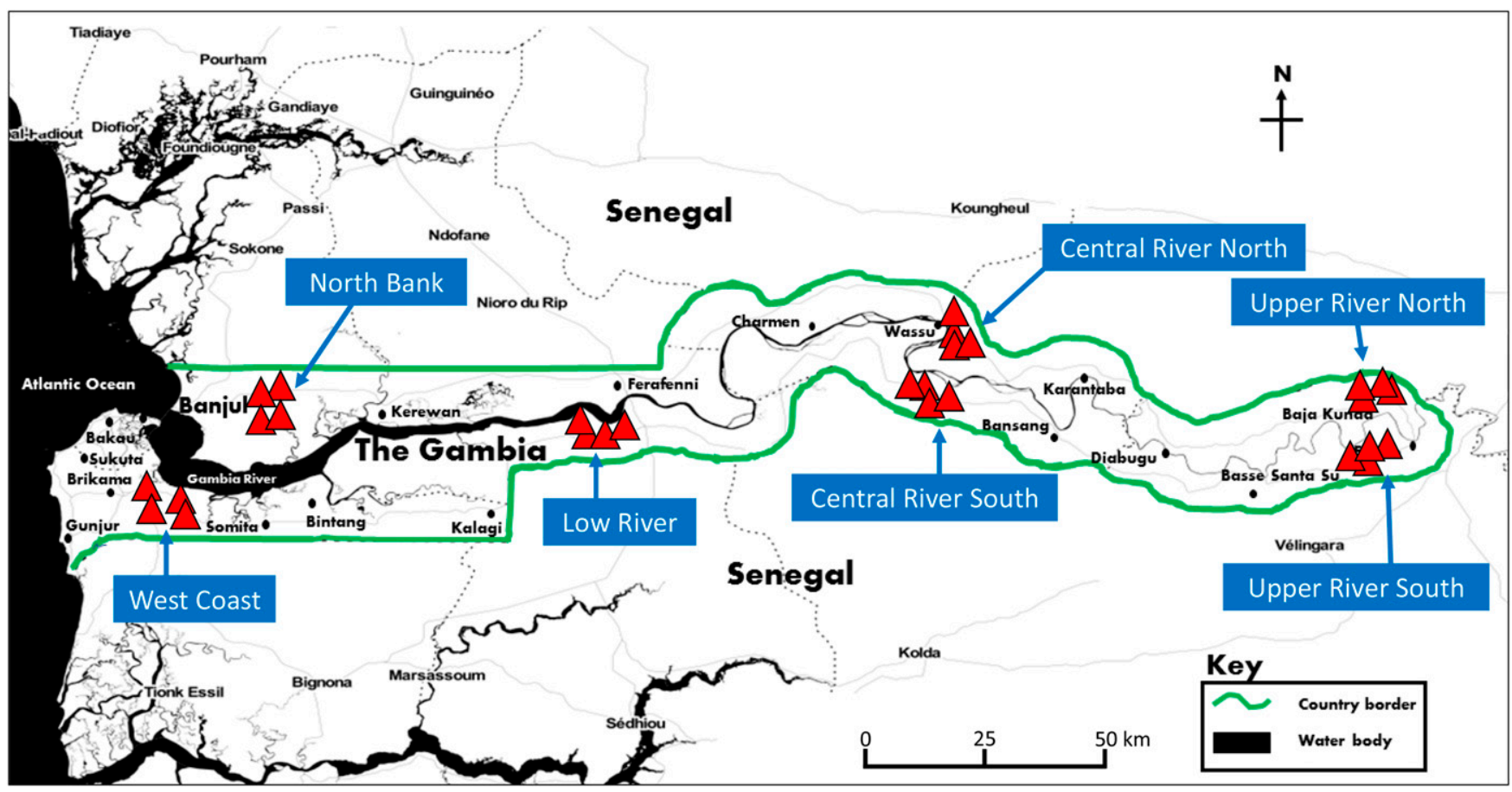

Fig. 1. Map of The Gambia showing sample collection sites for baseline aflatoxin analysis in groundnut, January 2013. In each region, four villages were visited, and five samples were collected from each village.

Table 1. Aflatoxin concentration in groundnut samples collected in seven regions of The Gambia in 2013

\begin{tabular}{|c|c|c|c|c|c|c|c|c|c|}
\hline \multirow[b]{2}{*}{ Region } & \multirow[b]{2}{*}{$\mathbf{n}$} & \multicolumn{4}{|c|}{ B aflatoxins (ppb) } & \multicolumn{4}{|c|}{ G aflatoxins (ppb) } \\
\hline & & $\operatorname{Min}^{\mathbf{y}}$ & Max & $\operatorname{Mean}^{\mathrm{z}}$ & Variance & Min & Max & Mean & Variance \\
\hline Central River North & 20 & ND & 570 & $70 \mathrm{ab}$ & 19,137 & ND & 588 & $33 \mathrm{ab}$ & 17,182 \\
\hline Central River South & 20 & ND & 246 & $37 \mathrm{ab}$ & 4,310 & ND & 23 & $2 a b$ & 29 \\
\hline Lower River & 20 & ND & 19 & $2 \mathrm{~b}$ & 25 & ND & 11 & $0.5 \mathrm{~b}$ & 6 \\
\hline North Bank & 20 & ND & 357 & $79 \mathrm{ab}$ & 15,417 & ND & 206 & $23 \mathrm{ab}$ & 8,898 \\
\hline Upper River North & 20 & ND & 44 & $4 \mathrm{~b}$ & 98 & ND & 14 & $0.7 \mathrm{ab}$ & 10 \\
\hline Upper River South & 20 & ND & 208 & $16 \mathrm{~b}$ & 2,145 & ND & 5 & $0.2 \mathrm{~b}$ & 1 \\
\hline West Coast & 20 & ND & 1,411 & $195 \mathrm{a}$ & 166,085 & ND & 578 & $73 \mathrm{a}$ & 21,128 \\
\hline LSD & & & & 0.5 & & & & 0.4 & \\
\hline
\end{tabular}

${ }^{y}$ ND: not detected. Limit of detection $=1$ ppb. Aflatoxins were extracted as previously described (Agbetiameh et al. 2018; Atehnkeng et al. 2008) and quantified with a scanning densitometer as previously described (Cotty and Cardwell 1999; Probst and Cotty 2012).

${ }^{\mathrm{z}}$ Means separation of log-transformed aflatoxin concentrations was conducted using Fisher's protected LSD test $(\alpha=0.05)$. Values followed by different letters differ significantly. 
Manufacturing Plant using an industrial process previously described (Agbetiameh et al. 2020). Briefly, to prepare the biocontrol product, sterile sorghum grain was coated with a suspension containing spores of the four atoxigenic isolates, a blue food colorant to differentiate the product from regular sorghum, and a polymer that aids in the coating process. The quality of the product (purity, sporulation capacity, and composition of the active ingredient fungi) was determined as previously described (Senghor et al. 2020). The finished formulated product was placed in $2.5 \mathrm{~kg}$ polyethylene bags, sealed, and transported (by sea-freight) to Dakar, Senegal, under appropriate export permit from NAQS and import permit from DPV Senegal. Then, the product was transported by road from Senegal to The Gambia.

Field plots and biocontrol application for effectiveness trials. The biocontrol product was applied in maize and groundnut fields in four regions of The Gambia during the 2014 and 2015 cropping seasons (Table 5) in collaboration with members of farmers' associations. All farmers voluntarily consented to conduct the effectiveness trials. In 2014, maize fields were treated in CRN, and groundnut fields were treated in CRN, NB, and WC. In 2015, maize fields were treated in both CRN and LR, and in groundnut fields in CRN, NB, and WC. The number of biocontrol-treated and untreated fields is given in Table 5.

During this part of the research, farmers were advised to grow their crops according to their traditional agronomic practices to test the value of biocontrol as a standalone management strategy in the real world. Groundnut farmers planted either $28-206$ or 73-33, two of the most common groundnut varieties in The Gambia. The former is a late-maturity variety (125 day growing cycle; flowering time around 45 days after planting) while the latter is an intermediatematuring variety (115 day growing cycle; flowering time around 40 days after planting) (ICRISAT 1990). Maize farmers planted diverse improved or landrace varieties with flowering time around 60 to 75 days after planting. In general, both crops were planted after the first rains during the first two weeks of July and harvested during late October to the first half of November. In general, farmers' fields were weeded by hand and animal-drawn hoe, top-dressed with urea

Table 2. Frequencies and combined densities of Aspergillus species associated with groundnut collected in seven regions of The Gambia in 2013

\begin{tabular}{|c|c|c|c|c|c|c|c|}
\hline \multirow[b]{2}{*}{ Region } & \multirow[b]{2}{*}{$\mathbf{n}$} & \multicolumn{5}{|c|}{ Aspergillus species distribution $(\%)^{\mathrm{y}}$} & \multirow[b]{2}{*}{$\mathrm{CFU} / \mathrm{g}^{\mathbf{z}}$} \\
\hline & & $\mathbf{L}$ & $\mathbf{S}_{\mathbf{B}}$ & $S_{\text {BG }}$ & $\mathbf{P}$ & $\mathbf{T}$ & \\
\hline Central River North & 240 & $83.8 \mathrm{ab}$ & $0.4 \mathrm{a}$ & $15.4 \mathrm{bc}$ & $0.0 \mathrm{~b}$ & $0.4 \mathrm{a}$ & $31,971 \mathrm{~b}$ \\
\hline Central River South & 240 & $85.0 \mathrm{a}$ & $0.0 \mathrm{a}$ & $12.9 \mathrm{c}$ & $2.1 \mathrm{a}$ & $0.0 \mathrm{a}$ & $97,791 \mathrm{ab}$ \\
\hline Lower River & 204 & $71.1 \mathrm{ab}$ & $0.0 \mathrm{a}$ & $28.9 \mathrm{bc}$ & $0.0 \mathrm{~b}$ & $0.0 \mathrm{a}$ & $1,089 \mathrm{~b}$ \\
\hline North Bank & 216 & $58.3 \mathrm{bc}$ & $0.5 \mathrm{a}$ & $41.2 \mathrm{ab}$ & $0.0 \mathrm{~b}$ & $0.0 \mathrm{a}$ & $247,589 a b$ \\
\hline Upper River North & 240 & $80.8 \mathrm{ab}$ & $0.0 \mathrm{a}$ & $19.2 \mathrm{bc}$ & $0.0 \mathrm{~b}$ & $0.0 \mathrm{a}$ & $1,428 \mathrm{~b}$ \\
\hline Upper River South & 228 & $81.6 \mathrm{ab}$ & $0.0 \mathrm{a}$ & $18.4 \mathrm{bc}$ & $0.0 \mathrm{~b}$ & $0.0 \mathrm{a}$ & $4,457 \mathrm{~b}$ \\
\hline West Coast & 240 & $42.9 \mathrm{c}$ & $0.0 \mathrm{a}$ & $57.1 \mathrm{a}$ & $0.0 \mathrm{~b}$ & $0.0 \mathrm{a}$ & 246,425 a \\
\hline Average & & 72.0 & 0.2 & 27.4 & 0.3 & 0.1 & 90,107 \\
\hline
\end{tabular}

${ }^{\mathrm{y}} \mathrm{L}$ : A. flavus $\mathrm{L}$ morphotype; $\mathrm{S}_{\mathrm{B}}$ : fungi with $\mathrm{S}$ morphotype producing only $\mathrm{B}$ aflatoxins; $\mathrm{S}_{\mathrm{BG}}$ : fungi with $\mathrm{S}$ morphotype producing both $\mathrm{B}$ and $\mathrm{G}$ aflatoxins; $\mathrm{P}: A$. parasiticus; T: A. tamarii. Means separation of Aspergillus species frequencies was conducted using Fisher's protected LSD test $(\alpha=0.05)$. Values followed by different letters differ significantly.

${ }^{\mathrm{z}}$ Colony forming units per gram.

Table 3. Aflatoxin-producing potentials of aflatoxigenic fungi associated with groundnut collected in seven regions of The Gambia in 2013

\begin{tabular}{|c|c|c|c|c|c|c|}
\hline \multirow[b]{2}{*}{ Region } & \multicolumn{3}{|c|}{ B aflatoxins (ppb) } & \multicolumn{3}{|c|}{ G aflatoxins (ppb) } \\
\hline & $n^{y}$ & Range & $\operatorname{Mean}^{\mathbf{z}}$ & $\mathbf{n}$ & Range & Mean \\
\hline Central River North & 209 & $8-7,842$ & $1,638 \mathrm{bc}$ & 38 & $308-4,609$ & $1,878 a b c$ \\
\hline Central River South & 213 & $7-9,932$ & $1,587 \mathrm{bc}$ & 36 & $61-4,444$ & $1,379 \mathrm{c}$ \\
\hline Lower River & 185 & $5-8,153$ & $2,012 \mathrm{ab}$ & 59 & $98-5,110$ & $2,171 \mathrm{ab}$ \\
\hline North Bank & 196 & $16-6,289$ & $2,019 \mathrm{ab}$ & 89 & $44-6,764$ & $1,907 \mathrm{abc}$ \\
\hline Upper River North & 220 & $7-9,478$ & $2,373 \mathrm{a}$ & 46 & $98-14,101$ & $2,365 \mathrm{a}$ \\
\hline Upper River South & 183 & $6-10,631$ & $1,564 \mathrm{c}$ & 42 & $319-3,744$ & $1,564 \mathrm{bc}$ \\
\hline West Coast & 233 & $15-8,989$ & 2,431 a & 137 & $155-4,891$ & $2,031 \mathrm{abc}$ \\
\hline
\end{tabular}

${ }^{y}$ Number of Aspergillus isolates, regardless of corresponding species, producing the indicated toxins in each region.

${ }^{z}$ Means separation of mean aflatoxin production potentials in each region was conducted using Fisher's protected LSD test $(\alpha=0.05)$. Values followed by different letters differ significantly.

Table 4. Number of atoxigenic Aspergillus flavus L morphotype isolates detected in seven regions of The Gambia and number of isolates belonging to the atoxigenic African A. flavus vegetative compatibility groups (AAVs) to which the active ingredient fungi of Aflasafe SN01 belong

\begin{tabular}{|c|c|c|c|c|c|}
\hline \multirow[b]{2}{*}{ Region } & \multirow{2}{*}{$\begin{array}{c}\text { Number of atoxigenic } L \\
\text { morphotype isolates }\end{array}$} & \multicolumn{4}{|c|}{ Members of Aflasafe SN01 AAVs ${ }^{\mathrm{z}}$} \\
\hline & & SS19-14 & MS14-19 & M2-7 & M21-11 \\
\hline Central River North & 31 & - & 1 & 1 & - \\
\hline Central River South & 27 & 1 & - & - & - \\
\hline Lower River & 19 & - & - & - & - \\
\hline North Bank & 20 & - & - & - & - \\
\hline Upper River North & 20 & - & - & 1 & - \\
\hline Upper River South & 45 & 4 & - & 2 & 1 \\
\hline West Coast & 7 & - & - & 1 & - \\
\hline
\end{tabular}

\footnotetext{
${ }^{\mathrm{z}}$ Frequencies of the atoxigenic Aflasafe SN01 AAVs were determined using vegetative compatibility analyses based on nitrate nonutilizing mutants of all the
} recovered A. flavus L morphotype isolates. 
(for maize) or a complex fertilizer (for groundnut and maize), and earthed-up (i.e., piling up soil around the base of the plants) before application of the biocontrol product to avoid burying it. No other agronomic interventions were made.

Farmers were trained on biocontrol product broadcasting techniques as described by Senghor et al. (2020). The product was broadcasted by hand at a rate of $10 \mathrm{~kg} / \mathrm{ha}$. Each year, biocontrol application was done 2 to 3 weeks before flowering for maize and 30 to 35 days after planting for groundnut, depending on the crop and variety used. For each treated field, a neighboring field, managed by the same farmer and planted with the same variety, at least $500 \mathrm{~m}$ apart was selected as the corresponding untreated field. The physical separation reduced the movement of the atoxigenic isolates into untreated fields and crops (Bock et al. 2004). Field sizes ranged from 0.5 to 2 ha. Groundnut and maize cultivars varied from region to region. Production of crops in all fields was dependent on rainfalls, which were erratic.

Soil and crop sampling of effectiveness trials. Before biocontrol treatment, soil samples $(\sim 150 \mathrm{~g})$ were collected by subsampling each field across transects from three random (40 to 50 subsamples) locations to a depth of $2 \mathrm{~cm}$ (Cotty 1997). Samples were air-dried and then sent to IITA-Ibadan under import/export permits as described above. After arrival, samples were dried in a forced-air oven (2 days, $50^{\circ} \mathrm{C}$ ) and then transferred to a biosafety cabinet where soil clods were eliminated with a hammer and manually homogenized within plastic bags.

Crops were harvested immediately after reaching physiological maturity to determine the influences of biocontrol application on both fungal community structure (soil and kernels) and the effectiveness in reducing aflatoxin contamination in treated crops compared with untreated crops. From each field, a $\sim 2 \mathrm{~kg}$ sample was collected. In 2014, an additional $\sim 1 \mathrm{~kg}$ sample was collected 3 months after harvest, from the store of each farmer to evaluate the influence of storage on aflatoxin contamination in both treated and untreated crops. All samples were transferred to DPV Senegal Plant Pathology laboratory, milled using a blender as above, and then sent to IITA-Ibadan for aflatoxin and microbiological analyses.
Fungal identification in biocontrol effectiveness trials. Fungi belonging to Aspergillus section Flavi were recovered and assigned to their corresponding species as described above except that instead of selecting 12 isolates per sample, 16 isolates were selected. Isolates were saved as described above. Mutant generation, mutant saving, and VCA were conducted as described above.

Field plots and biocontrol application in commercial trials. In 2018, the biocontrol product was applied in commercial groundnut fields of CRN, NB, and WC. There were 15 treated fields in each of the three regions, and for each treated field there was an untreated control field located at least $500 \mathrm{~m}$ apart. Treated and corresponding untreated fields were managed by the same farmer and planted with the same variety. The size of the fields ranged from 1 to 6 ha. The biocontrol product was produced, transported to The Gambia, and applied as described above.

In-situ aflatoxin quantification in commercial crops. Aflatoxin extraction and quantification were conducted in the farmer fields after harvest. For this, a GIPSA-approved Neogen Reveal Q+ for Aflatoxin kit (Neogen Corp., Lansing, MI) was used. Briefly, $2 \mathrm{~kg}$ of groundnut was randomly collected, milled as described above, and a 5-g subsample was transferred into a $500 \mathrm{ml}$ media bottle, and $100 \mathrm{ml} 65 \%$ ethanol was added. The mixture was shaken by hand for $3 \mathrm{~min}$ and allowed to settle for $3 \mathrm{~min}$. Then the mixture was filtered through Whatman No. 1 filter paper into a Tri-Pour beaker. Thereafter, $500 \mathrm{ml}$ of sample diluent was transferred to a sample cup and $100 \mathrm{ml}$ of sample filtrate was added. A $100 \mathrm{ml}$ aliquot of diluted sample was transferred into a new cup and mixed thoroughly and mixed by aspiration. A lateral flow strip was placed in the sample cup for $6 \mathrm{~min}$, and then the strip was read on a Neogene AccuScan Gold Reader. The limit of detection was $1 \mathrm{ppb}$ total aflatoxin.

Data analysis. Data on aflatoxin concentration, Aspergillus species distribution, $\mathrm{CFU} / \mathrm{g}$, and incidences of Aflasafe SN01 AAVs (response variable, $x$ ) were transformed using the equation $y=$ $\log _{10}(1+x)$ to stabilize the variance. For the baseline study, means were subjected to analysis of variance (ANOVA) and separated with Fisher's protected least significant difference (LSD) test $(\alpha=0.05)$. For the biocontrol treatment comparisons, means were separated

Table 5. Total aflatoxin concentration in Aflasafe SN01-treated and untreated crops at harvest during 2014 and 2015 in four regions of The Gambia. Evaluation after 3-month storage was conducted only in 2014.

\begin{tabular}{|c|c|c|c|c|c|c|c|c|c|c|c|c|c|c|}
\hline \multirow[b]{3}{*}{ Year } & \multirow[b]{3}{*}{ Regionw } & \multirow[b]{3}{*}{ Crop } & \multirow[b]{3}{*}{ Treatment } & \multirow[b]{3}{*}{$\mathbf{n}$} & \multicolumn{10}{|c|}{ Total aflatoxin concentration (ppb) } \\
\hline & & & & & \multicolumn{5}{|c|}{ At harvest } & \multicolumn{5}{|c|}{ After storage } \\
\hline & & & & & $\operatorname{Min}^{x}$ & Max & Mean $^{y}$ & Variance & Reduction $(\%)^{\mathbf{z}}$ & Min & $\operatorname{Max}$ & Mean & Variance & Reduction (\%) \\
\hline \multirow[t]{8}{*}{2014} & $\mathrm{CRN}$ & Maize & Treated & 20 & ND & 28 & $2.6^{* * *}$ & 51 & 94.8 & ND & 5 & $0.7 * * *$ & 2 & 98.1 \\
\hline & & & Untreated & 20 & ND & 314 & 48.9 & 5,351 & - & ND & 274 & 39.0 & 4,054 & \\
\hline & CRN & Groundnut & Treated & 14 & ND & 6 & 0.4 & 2 & 82.1 & ND & 43 & $2.9 *$ & 120 & 82.0 \\
\hline & & & Untreated & 14 & ND & 19 & 2.3 & 25 & - & ND & 127 & 16.2 & 1,483 & \\
\hline & NB & Groundnut & Treated & 15 & ND & 23 & $2.7 * *$ & 45 & 96.1 & ND & 6 & $1.2 *$ & 5 & 93.8 \\
\hline & & & Untreated & 15 & ND & 553 & 68.6 & 20,705 & - & ND & 126 & 19.7 & 1,434 & \\
\hline & WC & Groundnut & Treated & 15 & ND & 36 & 4.4 & 113 & 97.5 & ND & 90 & 14.6 & 854 & 77.4 \\
\hline & & & Untreated & 15 & ND & 1,727 & 172.9 & 231,432 & - & ND & 356 & 64.7 & 13,016 & \\
\hline \multirow[t]{10}{*}{2015} & CRN & Maize & Treated & 8 & ND & 47 & $16.0^{*}$ & 251 & 79.8 & - & - & - & - & - \\
\hline & & & Untreated & 8 & 10 & 227 & 79.3 & 7,605 & - & - & - & - & - & - \\
\hline & LR & Maize & Treated & 12 & ND & 29 & $6.5^{* * *}$ & 103 & 83.3 & - & - & - & - & - \\
\hline & & & Untreated & 12 & 4 & 168 & 39.0 & 2,512 & - & - & - & - & - & - \\
\hline & CRN & Groundnut & Treated & 15 & ND & ND & $0.0 *$ & 0 & 100 & - & - & - & - & - \\
\hline & & & Untreated & 15 & ND & 379 & 64.5 & 15,594 & - & - & - & - & - & - \\
\hline & NB & Groundnut & Treated & 15 & ND & ND & $0.0^{*}$ & 0 & 100 & - & - & - & - & - \\
\hline & & & Untreated & 15 & ND & 23 & 3.4 & 53 & - & - & - & - & - & - \\
\hline & WC & Groundnut & Treated & 15 & ND & ND & 0.0 & 0 & 100 & - & - & - & - & - \\
\hline & & & Untreated & 15 & ND & 97 & 9.9 & 757 & - & - & - & - & - & - \\
\hline
\end{tabular}

w CRN: Central River North, NB: North Bank, WC: West Coast, LR: Lower River.

${ }^{x}$ ND: not detected. Aflatoxins were extracted as previously described (Agbetiameh et al. 2018; Atehnkeng et al. 2008) and quantified with a scanning densitometer as previously described (Cotty and Cardwell 1999; Probst and Cotty 2012). Limit of detection = 1 ppb. For the purpose of the calculations, ND was considered $0 \mathrm{ppb}$.

y Means of aflatoxin values were compared independently between treated and untreated samples in each region, in each year. Treated values with one, two, or three asterisks $(*)$ significantly differed from their corresponding untreated treatment by Student's $t$ test $(\alpha=0.05,0.001$, and 0.0001 , respectively).

z Percent reduction was calculated for each region in each year as follows: ([mean of untreated - mean of Aflasafe SN01-treated]/mean of untreated) $\times 100$. 
using paired Student $t$ tests $(\alpha=0.05)$; in all cases, values of respective treated and untreated fields were compared. All statistical tests were conducted with SAS version 9.2 (SAS Institute Inc., Cary, NC).

\section{Results}

Aflatoxin concentration in groundnut sampled across The Gambia. Aflatoxin B and $\mathrm{G}$ varied among regions (Table 1). A total of 58 samples had no detectable aflatoxin content, and per region, these ranged from five (URN) to $14(\mathrm{LR})$. WC had the highest $(P<0.05)$ average aflatoxins (195 ppb of B and $73 \mathrm{ppb}$ of G) while LR had the lowest average aflatoxins ( $2 \mathrm{ppb}$ of $\mathrm{B}$ and $0.5 \mathrm{ppb}$ of $\mathrm{G}$; Table 1).

Aspergillus section Flavi fungi in the groundnut samples. A total of 1,608 Aspergillus section Flavi isolates were recovered from
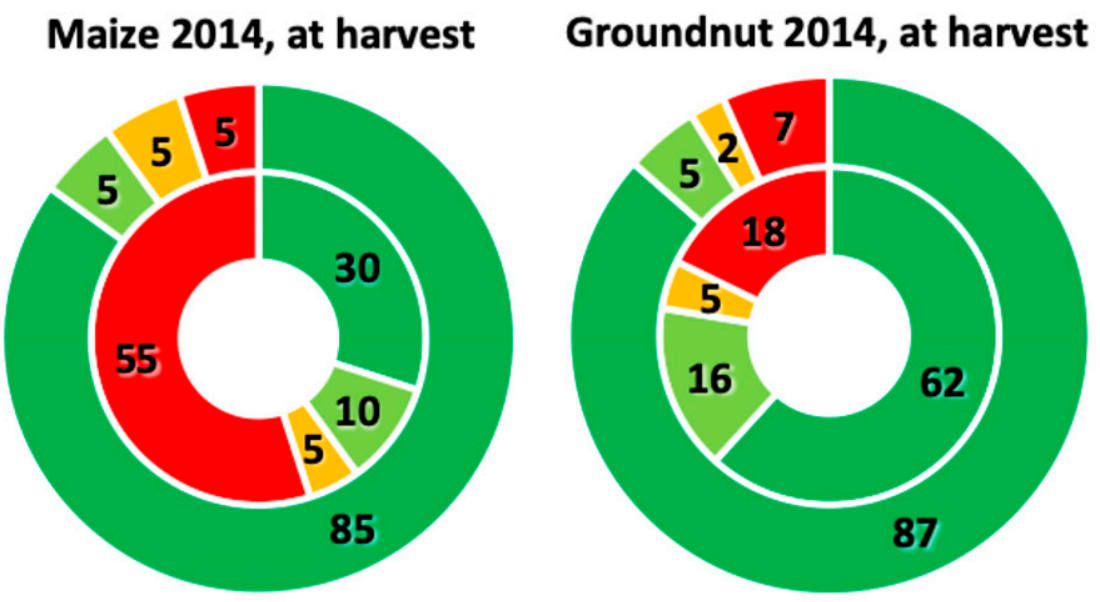

Maize 2014, after storage

\section{Groundnut 2014, after storage}
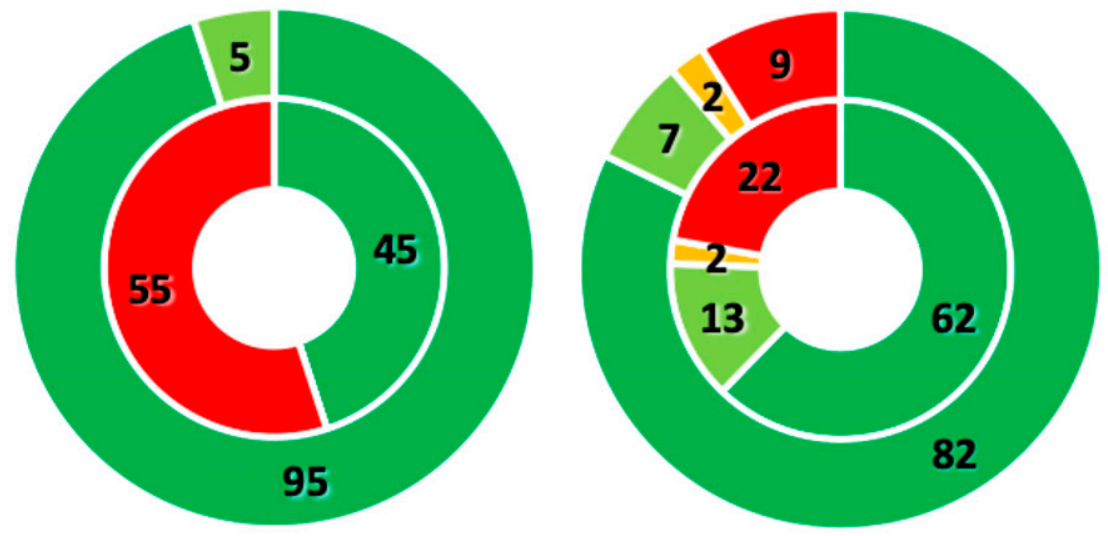

Maize 2015, at harvest

Groundnut 2015, at harvest
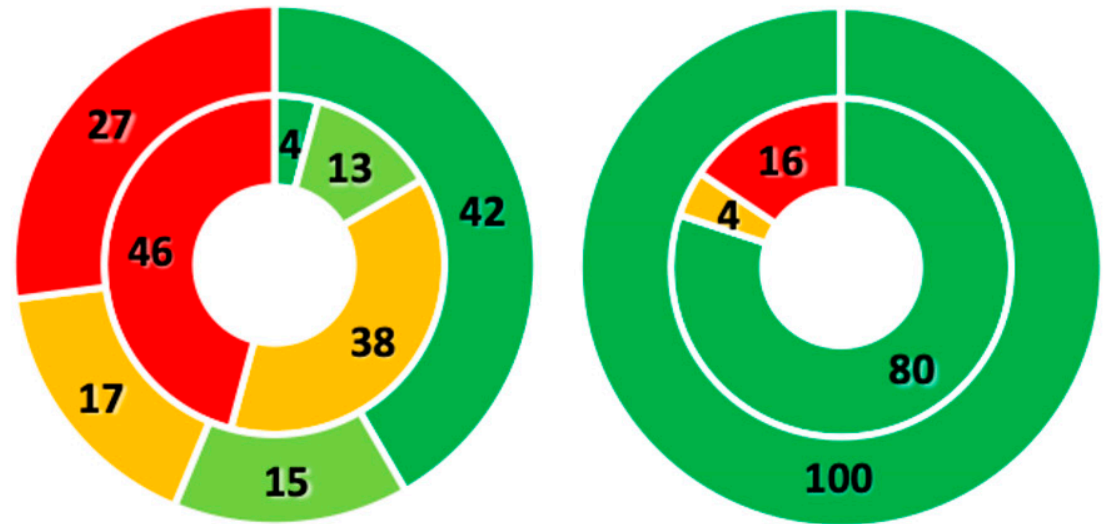

\section{$<4 \mathrm{ppb} \quad 4$ to $<10 \mathrm{ppb}$}

10 to $<20 \mathrm{ppb}$

\section{$>20 \mathrm{ppb}$}

Fig. 2. Percentage of groundnut and maize crops in each of four total aflatoxin concentration categories indicated by different colors. The outer circle shows Aflasafe SN01-treated crops while the inner circle shows untreated crops. In 2015 , evaluations after storage were not conducted. 
the groundnut. A. flavus $\mathrm{L}$ morphotype isolates produced smooth green-olive conidia and few, large sclerotia $(>400 \mu \mathrm{m})$ (Cotty 1989). Isolates producing copious small sclerotia $(<400 \mu \mathrm{m})$ and resembling the A. flavus $\mathrm{S}$ morphotype were classified as $\mathrm{S}$ morphotype-like fungi pending their status of aflatoxin-production ability (see below). A. parasiticus and A. tamarii were detected in some samples and were identified by their characteristic colony color and spore ornamentation (Klich and Pitt 1988).

The L morphotype dominated the communities in all regions (up to $85 \%$, CRS), except in WC $(42.9 \%)$, where $\mathrm{S}_{\mathrm{BG}}$ strains had a frequency of $57.1 \%$ (Table 2). The frequency of $S_{B G}$ strains ranged from 12.9 to $57.1 \%$. A parasiticus was detected only in samples from CRS $(2.1 \%)$ while $A$. tamarii was detected in a single sample from CRN (Table 2). There were two isolates with $S$ morphotype that produced only B aflatoxins, one isolate each in CRN and NB; those isolates were classified as $S_{B}$ strains. Fungal densities varied per region ranging from less than $4,500 \mathrm{CFU} / \mathrm{g}$ to over 245,000 CFU/g (Table 2).
Aflatoxin production of the recovered Aspergillus fungi. The large majority $(89.5 \%)$ of the recovered Aspergillus isolates (1,608 total) produced varying aflatoxin levels (Table 3). All A. parasiticus isolates produced both $\mathrm{B}$ and $\mathrm{G}$ aflatoxins, as expected. As mentioned above, all except two isolates with $\mathrm{S}$ morphotype produced both B and $\mathrm{G}$ aflatoxins (Table 2). The sole $A$. tamarii isolate recovered did not produce aflatoxins, as expected. Across the seven regions, 169 A. flavus L morphotype isolates did not produce aflatoxins. The range of atoxigenic isolates per region was 7 to 45 (Table 4).

Membership of atoxigenic fungi in AAVs composing the biocontrol product. None of the aflatoxin-producing L morphotype isolates belonged to the atoxigenic AAVs composing the biocontrol product. Among the 169 atoxigenic L morphotype fungi, 12 isolates (7.1\% among the atoxigenic fungi) belonged to one of the four atoxigenic AAVs (Table 4). There was one member each of atoxigenic AAVs MS14-19 and M21-11, while there were five members each of atoxigenic AAVs SS19-14 and M2-7. AAV

Table 6. Population densities of Aspergillus section Flavi in soil, maize, and groundnut grain of Aflasafe SN01-treated and untreated fields during 2014 and 2015 in four regions of The Gambia

\begin{tabular}{|c|c|c|c|c|c|c|}
\hline \multirow[b]{3}{*}{$\operatorname{Region}^{\mathrm{y}}$} & \multirow[b]{3}{*}{ Crop } & \multirow[b]{3}{*}{ Treatment } & \multicolumn{4}{|c|}{$\mathrm{CFU} / \mathrm{g}^{\mathrm{z}}$} \\
\hline & & & \multicolumn{2}{|c|}{2014} & \multicolumn{2}{|c|}{2015} \\
\hline & & & Soil before inoculation & Grain at harvest & Soil before inoculation & Grain at harvest \\
\hline \multirow[t]{2}{*}{ CRN } & Maize & Treated & 442 & $3,349,206$ & 289 & $1,279,181$ \\
\hline & & Untreated & 584 & $35,877,341$ & 373 & 333,748 \\
\hline \multirow[t]{2}{*}{ LR } & Maize & Treated & - & - & 172 & 408,953 \\
\hline & & Untreated & - & - & 168 & $47,318,086$ \\
\hline \multirow[t]{2}{*}{ CRN } & Groundnut & Treated & 1,980 & $53 *$ & 874 & 12,938 \\
\hline & & Untreated & 808 & 1,113 & 964 & 36,115 \\
\hline \multirow[t]{2}{*}{ NB } & Groundnut & Treated & 281 & 776,368 & 343 & 5,139 \\
\hline & & Untreated & 270 & 134,475 & 234 & 14,025 \\
\hline \multirow[t]{2}{*}{ WC } & Groundnut & Treated & 214 & 34,886 & 353 & 2,270 \\
\hline & & Untreated & 346 & $7,174,411$ & 903 & 2,780 \\
\hline
\end{tabular}

y CRN: Central River North, LR: Lower River, NB: North Bank, WC: West Coast.

${ }^{z} \mathrm{CFU} / \mathrm{g}$ : colony-forming units per gram of soil or grain. Values of treated soil before inoculation and grain at harvest with an asterisk significantly differed from those of the corresponding untreated treatments by Student's $t$ test $(\alpha=0.05)$.

Table 7. Frequencies of Aspergillus section Flavi fungi in soil, maize, and groundnut grains of Aflasafe SN01-treated and untreated fields in four regions of The Gambia during 2014 and 2015

\begin{tabular}{|c|c|c|c|c|c|c|c|c|c|}
\hline \multirow[b]{3}{*}{ Year } & \multirow[b]{3}{*}{ Region $y$} & \multirow[b]{3}{*}{ Crop } & \multirow[b]{3}{*}{ Treatment } & \multicolumn{6}{|c|}{ Aspergillus species distribution $(\%)^{\mathrm{z}}$} \\
\hline & & & & \multicolumn{3}{|c|}{ Soil before inoculation } & \multicolumn{3}{|c|}{ Grain at harvest } \\
\hline & & & & $\mathbf{L}$ & $\mathbf{S}_{\mathrm{BG}}$ & $\mathbf{T}$ & $\mathbf{L}$ & $\mathbf{S}_{\mathrm{BG}}$ & $\mathbf{T}$ \\
\hline \multirow[t]{8}{*}{2014} & $\mathrm{CRN}$ & Maize & Treated & 95.0 & 0.0 & 5.0 & 100.0 & 0.0 & $\overline{0.0}$ \\
\hline & & & Untreated & 100.0 & 0.0 & 0.0 & 100.0 & 0.0 & 0.0 \\
\hline & CRN & Groundnut & Treated & 100.0 & 0.0 & 0.0 & 92.0 & 7.0 & 1.0 \\
\hline & & & Untreated & 97.0 & 2.0 & 1.0 & 72.0 & 28.0 & 0.0 \\
\hline & NB & Groundnut & Treated & 95.0 & 0.0 & 5.0 & $84.0^{*}$ & $16.0^{*}$ & 0.0 \\
\hline & & & Untreated & 94.0 & 0.0 & 6.0 & 52.0 & 46.0 & 2.0 \\
\hline & WC & Groundnut & Treated & 91.0 & 1.0 & 8.0 & $89.0 *$ & $11.0^{*}$ & 0.0 \\
\hline & & & Untreated & 91.0 & 0.0 & 9.0 & 42.5 & 55.5 & 2.0 \\
\hline \multirow[t]{10}{*}{2015} & CRN & Maize & Treated & 100.0 & 0.0 & 0.0 & 100.0 & 0.0 & 0.0 \\
\hline & & & Untreated & 98.0 & 2.0 & 0.0 & 100.0 & 0.0 & 0.0 \\
\hline & LR & Maize & Treated & $97.0^{*}$ & 2.0 & 1.0 & 100.0 & 0.0 & 0.0 \\
\hline & & & Untreated & 91.0 & 4.0 & 5.0 & 99.0 & 1.0 & 0.0 \\
\hline & CRN & Groundnut & Treated & 100.0 & 0.0 & 0.0 & 89.0 & 11.0 & 0.0 \\
\hline & & & Untreated & 86.5 & 12.5 & 1.0 & 87.0 & 13.0 & 0.0 \\
\hline & NB & Groundnut & Treated & 99.0 & 0.0 & 1.0 & 72.0 & 28.0 & 0.0 \\
\hline & & & Untreated & 89.0 & 8.0 & 3.0 & 69.0 & 31.0 & 0.0 \\
\hline & WC & Groundnut & Treated & 96.0 & 0.0 & 4.0 & 83.0 & 17.0 & 0.0 \\
\hline & & & Untreated & 98.0 & 2.0 & 0.0 & 52.0 & 48.0 & 0.0 \\
\hline
\end{tabular}

y CRN: Central River North, NB: North Bank, WC: West Coast, LR: Lower River.

${ }^{\mathrm{z}} \mathrm{L}$ : Aspergillus flavus $\mathrm{L}$ morphotype; $\mathrm{S}_{\mathrm{BG}}$ : fungi with $\mathrm{S}$ morphotype producing B and $\mathrm{G}$ aflatoxins; $\mathrm{P}:$ A. parasiticus; $\mathrm{T}$ : A. tamarii. Values of treated soil before inoculation and grain at harvest with an asterisk significantly differed from those of the corresponding untreated treatments by Student's $t$ test $(\alpha=0.05)$. 
SS19-14 occurred in two regions, while AAV M2-7 occurred in four regions (Table 4).

Quality test of the biocontrol product. All grains from each biocontrol product examined batch yielded $100 \%$ of carrier grains colonized by A. flavus and only fungi belonging to one of the four AAVs were detected (data not shown). None of the grains contained any other microorganism. Each atoxigenic AAV composed $25 \% \pm 3 \%$ of the communities recovered from the carrier grains. The number of spores per $\mathrm{g}$ of biocontrol product was, on average, $3,500 \pm 300$.

Aflatoxin content at harvest and after storage from smallholder effectiveness trials. In 2014, at harvest, the average total aflatoxin was up to $4.4 \mathrm{ppb}$ in treated crops (range = ND to $4.4 \mathrm{ppb}$; Table 5) while the average aflatoxin in untreated crops ranged from 2.3 to $172.9 \mathrm{ppb}$ (Table 5). During that year, most untreated crops had unsafe, high aflatoxin levels with some samples containing $>300 \mathrm{ppb}$ and one with the hazardous content of $1,727 \mathrm{ppb}$. In 2015, treated maize had 6 and $16 \mathrm{ppb}$ total aflatoxin in LR and CRN, respectively (Table 5). None of the treated groundnut during $2015(n=45)$ was contaminated with aflatoxins while it ranged from 3 to $64 \mathrm{ppb}$ in untreated groundnut. In both years, there were 82 to $100 \%$ less aflatoxins in treated crops compared with untreated crops (Table 5).

In 2014, treated and untreated crops were tested for aflatoxin contamination 3 months after storage in farmer stores (Table 5). Treated crops accumulated significantly $(P<0.05)$ less aflatoxins (range $=$ 0.7 to $14.6 \mathrm{ppb}$ ) than untreated crops (range $=16.2$ to $64.7 \mathrm{ppb}$ ). Treated crops had 77.4 to $98.1 \%$ less aflatoxins than untreated crops after the storage period (Table 5).

At harvest, aflatoxin content variance in treated crops was 92 to $100 \%$ less than in untreated crops (Table 5). After storage (2014), aflatoxin content variance in treated crops was 89 to $99 \%$ less than in untreated crops (Table 5). Crops from biocontrol-treated fields contained higher proportions of samples with $<4 \mathrm{ppb}$ aflatoxin both at harvest and after storage (Fig. 2). In 2014, at harvest, the percentage of treated crops across regions with $<4$ ppb aflatoxin was $85 \%$ for maize and $87 \%$ for groundnut, while only $5 \%$ of maize and $7 \%$ of groundnut had $>20 \mathrm{ppb}$ aflatoxin. In 2015 , treated groundnut in all regions contained undetectable aflatoxin levels, while $42 \%$ of maize in the examined regions had $<4 \mathrm{ppb}$ aflatoxin. After storage (2014), $95 \%$ of the treated maize and $82 \%$ of the treated groundnut had $<4$ ppb aflatoxin.

In contrast, untreated maize and groundnut at harvest in 2014 had $55 \%$ and $18 \%$, respectively, of samples with $>20 \mathrm{ppb}$ aflatoxin (Fig. 2). After storage, $55 \%$ and $22 \%$ of untreated groundnut and maize samples, respectively, had $>20 \mathrm{ppb}$ aflatoxin. In 2015,16 to $46 \%$ of untreated crops at harvest had $>20 \mathrm{ppb}$ aflatoxin (Fig. 2).

Fungal densities in field effectiveness trials. Aspergillus spp. densities in soil before biocontrol application were generally low in both treated (range $=172$ to $1,980 \mathrm{CFU} / \mathrm{g}$ ) and untreated fields (range $=168$ to $964 \mathrm{CFU} / \mathrm{g}$ ). In both years, fungal densities did not differ $(P>0.05)$ in any of the comparisons (Table 6).

There were many cases in which grains from untreated crops at harvest had higher fungal densities (range $=1,113$ to $47.3 \times 10^{6}$ $\mathrm{CFU} / \mathrm{g}$ ) than treated fields (range $=53$ to $3.3 \times 10^{6} \mathrm{CFU} / \mathrm{g}$ )
(Table 6). However, in both years, fungal densities did not differ $(P>0.05)$ in any of the comparisons, except for groundnut in CRN where higher densities occurred in untreated grains (Table 6). Values of fungal densities were always higher in grains at harvest than in soils before inoculation, regardless of treatment.

Distribution of Aspergillus section Flavi in field effectiveness trials. The A. flavus $\mathrm{L}$ morphotype dominated both soils before inoculation (range $=91$ to $100 \%$ ) and crops at harvest (range $=72$ to $100 \%$ ) during each year (Table 7). Although aflatoxin-producing ability was not evaluated, all fungi with S morphotype were considered to produce $\mathrm{B}$ and $\mathrm{G}$ aflatoxins and therefore were called $S_{B G}$ strains; frequencies of $S_{B}$ strains in the baseline study were low (only two isolates) and thus no efforts were made to characterize the aflatoxin production profile of fungi with S morphotype in this portion of the research. Before inoculation in 2014, $\mathrm{S}_{\mathrm{BG}}$ strains were rarely detected and only isolated in untreated fields (range $=0$ to $2 \%$ ), A. parasiticus was not detected, while A. tamarii frequencies ranged from 0 to $9 \%$. In $2014, \mathrm{~S}_{\mathrm{BG}}$ strains were not detected in maize at harvest while in groundnut, $\mathrm{S}_{\mathrm{BG}}$ strains ranged from 7 to $16 \%$ in treated crops and from 28 to $55 \%$ in untreated crops (Table 7).

In 2015, the occurrence of $S_{B G}$ strains ranged from 0 to $2 \%$ in soils before application of biocontrol and from 2 to $13 \%$ in untreated plots. A. tamarii frequencies ranged from 0 to $5 \%$. At harvest in $2015, \mathrm{~S}_{\mathrm{BG}}$ strains were not detected in treated maize while in groundnut it ranged from 11 to $28 \%$ in the treated crops and from 13 to $48 \%$ in the untreated crops (Table 7). A. parasiticus was not detected in soils or grains of any given region, regardless of treatment.

Aflatoxin content in biocontrol effectiveness trials in commercially produced groundnut. In the three evaluated regions, the average aflatoxin concentration at harvest in biocontrol-treated groundnut ranged from 2.1 to $2.3 \mathrm{ppb}$ and none exceeded $4 \mathrm{ppb}$ (Table 8). Total aflatoxin in untreated crops at harvest on an average ranged from 12.8 to $53.1 \mathrm{ppb}$. Treated crops accumulated significantly $(P<0.0001)$ less aflatoxin $(82$ to $96 \%$ less) than untreated crops (Table 8). Aflatoxin variance in treated crops ranged from 0.1 to 0.4 while in untreated crops ranged from 92 to 1,846 . Variance in treated crops was $>99.5 \%$ lower than in untreated crops (Table 8).

\section{Discussion}

Human exposure to aflatoxins in The Gambia has been repeatedly quantified through urinary, blood, and breast milk analyses (Groopman et al. 1992; Wild et al. 1992; Zarba et al. 1992) and this exposure has been associated with growth faltering, immune suppression, and liver cancer (Kirk et al. 2006; Turner et al. 2003, 2007). However, very few studies have established aflatoxin levels in crops or foods in The Gambia. Two studies were conducted with very few samples and in another the origin of the samples is not clear (Hudson et al. 1992; Jallow et al. 2019; Xu et al. 2017). The current study is the first to establish a baseline for groundnut aflatoxin contamination across the country. In addition, the community structure of aflatoxinproducing fungi associated with groundnut was established and atoxigenic A. flavus native to The Gambia were identified for use in biocontrol products. Atoxigenic genotypes identified in the

Table 8. Total aflatoxin concentration in Aflasafe SN01-treated and untreated commercially produced groundnut at harvest during 2018 in three regions of The Gambia

\begin{tabular}{|c|c|c|c|c|c|c|c|c|}
\hline \multirow[b]{2}{*}{$\operatorname{Region}^{x}$} & \multirow[b]{2}{*}{ Treatment } & \multirow[b]{2}{*}{$\mathbf{n}$} & \multicolumn{5}{|c|}{ Total aflatoxin $(\mathbf{p p b})^{\mathrm{y}}$} & \multirow[b]{2}{*}{ Reduction $(\%)^{\mathrm{z}}$} \\
\hline & & & Min & Max & Mean & Variance & 95th percentile & \\
\hline \multirow[t]{2}{*}{ CRN } & Treated & 15 & 2 & 3 & $2.1 * * *$ & 0.1 & 3.0 & 96.0 \\
\hline & Untreated & 15 & 11 & 170 & 53.1 & $1,846.0$ & 135.0 & \\
\hline \multirow[t]{2}{*}{ NB } & Treated & 15 & 1 & 3 & $2.3^{* * *}$ & 0.4 & 3.0 & 82.0 \\
\hline & Untreated & 15 & 2 & 30 & 12.8 & 92.0 & 28.6 & \\
\hline \multirow[t]{2}{*}{ WC } & Treated & 15 & 2 & 4 & $2.3 * * *$ & 0.4 & 3.3 & 93.6 \\
\hline & Untreated & 15 & 12 & 71 & 35.9 & 292.0 & 63.3 & \\
\hline
\end{tabular}

\footnotetext{
${ }^{x}$ CRN: Central River North, NB: North Bank, WC: West Coast.

y Total aflatoxins were quantified using Neogen Reveal Q+ for Aflatoxin kit and Neogene AccuScan Gold Reader. Limit of detection $=1 \mathrm{ppb}$. Treated values with three asterisks $(* * *)$ significantly differed from their corresponding untreated treatment by Student's t-test $(\alpha=0.0001)$.

${ }^{\mathrm{z}}$ Percent reduction was calculated for each region as follows: ([mean of untreated - mean of Aflasafe SN01-treated]/mean of untreated) $\times 100$.
} 
current study are also in the biocontrol product Aflasafe SN01, originally isolated in Senegal, therefore allowing testing Aflasafe SNO1 in The Gambia. Extensive field tests revealed that the biocontrol product is highly effective in The Gambia at decreasing aflatoxin content at harvest and during storage. Treated crops accumulated 82 to $100 \%$ less aflatoxins than untreated crops. This is the first report of the use and effectiveness of an atoxigenic biocontrol product in a nation other than the nation from which the active ingredients were originally isolated.

The baseline survey of aflatoxin concentrations revealed that contaminated groundnut is a major contributor to aflatoxin exposure of consumers in The Gambia and the resulting disease such exposure causes (Castelino et al. 2014; Kuniholm et al. 2008; Turner et al. 2000). Results showed that some groundnut contained dangerous aflatoxin concentrations, up to $1,400 \mathrm{ppb}$ aflatoxin $\mathrm{B}_{1}$ (Table 1), and was associated with extremely toxigenic fungi (Tables 2 and 3 ). Apart from health problems reducing the well-being and productivity of affected populations, aflatoxins pose a significant challenge to crop producers and exporters in West Africa, including The Gambia, aiming to reach domestic and international premium markets (Bandyopadhyay et al. 2016; Shephard 2008).

A recent study reporting aflatoxin levels in groundnut from The Gambia $(n=1,168)$ during an 11 -year period (range $=0$ to 2,581 $\mathrm{ppb}$ ) found that $58 \%$ of the samples had aflatoxin below the 15 ppb Codex Alimentarius limit (Jallow et al. 2019). The study does not report the source of the samples (range per year $=13$ to 276) and it is unknown if samples are representative of the whole country. We argue that the study that we conducted across The Gambia is the first aflatoxin baseline study for any crop/food in the country. Jallow et al. (2019) quantified aflatoxins using a methodology relying in spotting aflatoxin extracts until matching the fluorescence of the standards rather than directly quantifying with densitometry as reported in the current study. Such method could have underestimated aflatoxin levels in some samples.

Aflatoxin management strategies have been researched on over many decades for diverse crops (Aoun et al. 2020; Campbell et al. 2003; Hell et al. 2003; Lillehoj et al. 1980; Udomkun et al. 2017b; Waliyar et al. 2008, 2015). In the developed world, effective aflatoxin mitigation strategies are implemented, such as regulatory infrastructure, supplemental irrigation, harvesting advisories, processing, testing, and the burden of contamination is generally minor compared with the developing world. In developing and emerging nations, aflatoxin management strategies are either seldom used or not effective, the regulatory infrastructure is insufficient to remove most contaminated foods, and populations become continuously exposed to unsafe aflatoxin levels (Bandyopadhyay et al. 2016; Hanlon et al. 2019; Udomkun et al. 2017a). If available, aflatoxin control technologies are frequently used in isolation rendering crops vulnerable to aflatoxin contamination because use of single or few technologies do not provide adequate protection throughout the value chain.

In neighboring Senegal, use of an aflatoxin biocontrol product allows groundnut and maize to be produced with significantly less aflatoxins than untreated crops, both at harvest and after storage (Senghor et al. 2020). The government of The Gambia requested support from Plant Protection Service of Senegal, IITA, and USDA-ARS, to capitalize on experience to identify atoxigenic fungi with potential as biocontrol agents and to test a biocontrol product in maize and groundnut.

Aflasafe SN01, developed for use in Senegal (Senghor et al. 2020), is a biocontrol product registered with CSP/CILSS, the agency responsible for pesticide registration in 13 nations of the Sahel region, including The Gambia. Registration with CSP/CILSS allows product use in all 13 nations. However, it is general policy not to use biocontrol outside the region of normal distribution of its active ingredients in order to ensure superior performance in the target agroecosystems and to avoid any concerns about negative effects of introducing exotic genotypes. To meet these concerns, the AAVs in Aflasafe SN01 were sought in crops produced in The Gambia. Among 169 atoxigenic isolates cultured, 12 were found to be one of the four active ingredients of the biocontrol product Aflasafe SN01, and these occurred in five of the seven regions (Table 4). Upon identification of the four active ingredients of Aflasafe SN01 in The Gambia, it was decided to avoid the time-consuming, resource-intensive process of identifying new active ingredients and to move directly into testing the product across The Gambia. The biocontrol product was tested during two cropping seasons in both groundnut and maize and was found to be highly efficient in limiting aflatoxin content by displacing aflatoxin producers (Tables 5, 6, and 7; Fig. 2). The product was also used by commercial farmers who reported excellent effectiveness with greater than $80 \%$ reductions in aflatoxin content and no more than $4 \mathrm{ppb}$ in any lot (Table 8). Overall, the current study supports biocontrol as an aflatoxin management tool that groundnut and maize growers in The Gambia can exploit to limit crop aflatoxin contamination, both at harvest and after storage.

The biocontrol product protected maize and groundnut throughout all critical phases of contamination with significantly reduced aflatoxin contamination both at harvest and after storage (Table 5). Furthermore, variance in aflatoxin content was always several-fold lower in treated crops compared with untreated (Table 5). Reduced variance in treated crops means less risk of aflatoxin contamination (Senghor et al. 2020). Biocontrol with atoxigenic fungi does not always result in total elimination of aflatoxins in treated crops (Bandyopadhyay et al. 2019; Senghor et al. 2020). However, in the current study, no aflatoxins were detected in any of the treated groundnut produced during 2015 (Table 5; Fig. 2). The observed highly significant reductions during the effectiveness trials (2014 and 2015) occurred in the absence of improved agronomic practices such as weeding fields on time, timely harvesting, drying groundnut in small heaps with pods avoiding contact with the soil (Waliyar et al. 2008), which may be expected to provide additional benefits (Bandyopadhyay et al. 2019). Aflatoxin levels in some crops were higher at harvest than after storage, for both treated and untreated crops, but there were no consistent trends (Table 5). However, there were no significant differences $(P>0.05$; Student's $t$-test) when either treated or untreated crops were compared at harvest and after storage. For example, on an average, aflatoxin levels in maize in CRN were $48.9 \mathrm{ppb}$ at harvest and $39.0 \mathrm{ppb}$ after storage, but these were not significantly different.

Regardless of treatment, farmers sorted the grains before storage, as per their practices. On one hand, sorting contributed to less aflatoxins after storage in untreated crops from three of the four comparisons. On the other hand, on an average, reductions resulting from sorting of untreated crops were in most cases insufficient to make aflatoxin content safe for consumption after the storage period (Table 5). Although sorting is an effective practice to remove mycotoxin contaminated grains (Aoun et al. 2020; Matumba et al. 2015), it does not always result in reducing aflatoxin content to acceptable levels and/or may concentrate aflatoxins in rejected grains that ultimately are consumed (Matumba et al. 2015). In The Gambia, groundnut purchased from markets were reported to contain substantially less aflatoxin when moldy kernels were separated $\mathrm{Xu}$ et al. 2017). In that study, a group of women, who traditionally sort the groundnut using different techniques, were trained to conduct the sorting process. Women participating in the current study were not given any training and their sorting practices were not monitored. The increased aflatoxin content in both treated and untreated groundnut in CRN and in treated groundnut in WC (Table 5) could be the result of improper sorting, more deficient storage practices than in other areas, high moisture content prior to storage, or a combination of those factors. Regardless, as stated before, none of the individual at harvest versus after storage comparisons were significantly different.

There is the notion that biocontrol treatment does not provide adequate postharvest protection (e.g., aflatoxin below $10 \mathrm{ppb}$ ) (Ehrlich et al. 2015; Gressel and Polturak 2018; Villers 2014), although postharvest benefits have been reported in the U.S. (Dorner and Cole 2002). Recently, that hypothesis was tested by subjecting maize from treated fields in the U.S. to a lab storage assay with uninterrupted aflatoxin formation conducive conditions ( 6 days, $28^{\circ} \mathrm{C}$ ). The experiment revealed that aflatoxin increased 
to unsafe levels (Kinyungu et al. 2019). In contrast, in our studies, the average aflatoxin content in sorted biocontrol-treated grains after a 3-month storage period using traditional practices resulted in safe aflatoxin levels in three regions (average range $=0.7$ to $2.9 \mathrm{ppb}$ ), while in the fourth region, the average concentration in treated, stored groundnut was $14.6 \mathrm{ppb}$. In contrast, aflatoxin in similarly sorted, stored untreated grains ranged from 16.2 to $64.7 \mathrm{ppb}$ (Table 5). Treated crops had considerably more (up to $100 \%$, depending on the crop and year) samples with $<4 \mathrm{ppb}$ aflatoxin while untreated crops sometimes had more than $50 \%$ of the samples with $>20 \mathrm{ppb}$ (Fig. 2). Use of biocontrol in Senegal over 5 years also resulted in treated, sorted grains $(n=268)$ containing on average less than $10 \mathrm{ppb}$ (range $=$ 0.5 to $9.9 \mathrm{ppb}$ ) after a 4-month storage period using traditional practices while average aflatoxin for sorted, stored, untreated grain $(n=$ 268) ranged from 10.1 to $64.9 \mathrm{ppb}$ (Senghor et al. 2020). Evaluation of postharvest benefits under artificial systems may not reliably estimate benefits of biocontrol in limiting aflatoxin content to below tolerance thresholds during real-life storage conditions. When simulating poor storage conditions, treated grains accumulate less aflatoxins than untreated grains, although experiments under artificial conditions sometimes yield stored treated crops with reduced but still unsafe aflatoxin levels (Atehnkeng et al. 2014; Bandyopadhyay et al. 2019). Ultimately, the level of postharvest protection provided by atoxigenic biocontrol agents will depend on factors such as climatic conditions, sorting practices, storage conditions, period of storage, insect control, and fungal load, among others.

Regardless of the biocontrol postharvest benefits detected in reallife studies conducted in Senegal and The Gambia, an integrated set of good preharvest and postharvest practices is included in the aflatoxin management system that IITA and partners promote in The Gambia and other nations. A system including good agronomic practices, biocontrol, sorting, drying, and improved storage and processing practices, along with policy and institutional solutions, will result in decrease aflatoxin content throughout the value chain.

Deliberate application of biocontrol organisms has raised concerns of the possibility of i) causing ecological imbalances affecting populations of microorganisms not targeted (Köhl et al. 2019) and, in the case of atoxigenic biocontrol products, ii) increased quantities of Aspergillus spp. throughout the environment that could increase kernel rot (Bhandari et al. 2020). However, the amount of Aspergillus spores in treated and untreated crops is dependent on environmental conditions and available resources for fungal reproduction and not primarily driven by biocontrol application (Bandyopadhyay et al. 2016). This was evident in 2014, where untreated maize in CRN had on an average 10 times more CFU/g than treated maize (Table 6). On the other hand, in the following year in CRN, there was a threefold fungal increase in treated compared with untreated maize although the densities $\left(1.3 \times 10^{6} \mathrm{CFU} / \mathrm{g}\right)$ were lower than in untreated maize during the previous year $\left(35.9 \times 10^{6} \mathrm{CFU} / \mathrm{g}\right.$, Table 6). In 2014, groundnut had over 20 times more CFU/g in untreated crops in two regions (Table 6). There were a few cases in which higher, but statistically similar fungal densities were detected in treated crops (Table 6).

The possibility of decreased fungal densities as a result of biocontrol treatment has not been discussed because a priori intuition suggests that biocontrol application will automatically increase the densities of Aspergillus spp. in the environment. On the other hand, in the absence of biocontrol application, densities of Aspergillus fungi can increase rapidly as a result of the exploitation of cropassociated nutrients and explosive, rapid reproduction driven by founder events of single or few A. flavus VCGs (Ortega-Beltran et al. 2020). Rapid reproduction and dispersal of few A. flavus VCGs have been detected in untreated areas over diverse, highly contrasting environments in Mexico (Ortega-Beltran and Cotty 2018). Also, in the U.S., subpopulations containing aflatoxin-producers and nontoxin producers were found across a vast area (Drott et al. 2019), which may have been caused by founder events as well. A rapid increase of few genotypes generated by founder events followed by intense clonal reproduction and efficient dispersal (Islam et al. 2018) may have occurred across some of the examined regions in The
Gambia and therefore higher fungal densities were detected in untreated crops (e.g., maize in CRN in 2014, Table 6). Research to determine VCG community structures in untreated soils and crops of the current study is needed to elucidate the complexity of genotypes responsible for the large population increases in untreated fields.

Biocontrol application appears, in crops from some regions, to have prevented the rapid increase of one or a few genotypes occurring in neighboring, untreated fields. One of the principles of the biocontrol technology is that the timely introduction of biocontrol genotypes restricts the reproduction of populations with greater aflatoxin-producing potential through competitive exclusion (Cotty 2006; Mehl et al. 2012). Competitive exclusion thus prevents natural increases of highly toxigenic Aspergillus spp. communities, regardless of the magnitude of increase supported by the local environment and resources. There will be some areas or years where large increases in nearby untreated crops will not occur and therefore either equal or greater fungal densities will be detected in treated crops compared with untreated crops. Biocontrol treatment in Senegal over 5 years did result in higher $(P<$ $0.05)$ fungal densities in treated crops of some areas, in certain years (Senghor et al. 2020).

The proportion of Aspergillus species in soils before treatment across areas and years were generally similar in treated and untreated fields across regions, crops, and years (Table 7). Both treated and untreated soils where maize was evaluated contained low frequencies of $\mathrm{S}_{\mathrm{BG}}$ strains and in grains at harvest, maize was dominated by the $\mathrm{L}$ morphotype, with $\mathrm{S}_{\mathrm{BG}}$ strains only detected in a few fields of $\mathrm{LR}$ in 2015 (Table 7). Thus, influences of treatments on $S_{B G}$ strain incidence in maize could not be evaluated. On the other hand, there were significant differences in proportions of both the L morphotype and $\mathrm{S}_{\mathrm{BG}}$ strains in treated and untreated groundnut. Proportions of $\mathrm{S}_{\mathrm{BG}}$ strains were consistently lower in treated groundnut, particularly when $S_{B G}$ strains were high in untreated crops (Table 7). In the current study, low frequencies of the highly toxigenic species A. parasiticus were detected (Tables 2 and 7). This species is infrequently associated with groundnut cropped in The Gambia. Similar poor association of $A$. parasiticus with groundnut has been reported in Senegal and Ghana (Agbetiameh et al. 2018, 2020; Senghor et al. 2020). In other groundnut-producing regions, A. parasiticus is a more important member of the aflatoxin-producing communities (Horn 2003; Kachapulula et al. 2017b; Klich 2007).

After the field effectiveness stage and registration, the biocontrol product has been used commercially. In the 2018 cropping season, commercial farmers belonging to the National Food Security Processing and Marketing Corporation (NFSPMC) of The Gambia treated 5,000 ha of groundnut as a part of an integrated aflatoxin management strategy mentioned earlier. Performance of the biocontrol was monitored at harvest in groundnut from 45 treated fields and paired untreated fields. All treated groundnut had sufficient quality to be commercialized in the most stringent markets $(<4$ ppb total aflatoxin), while a large proportion of untreated groundnut failed to reach safe aflatoxin levels (Table 8). Indeed, part of the biocontrol-treated groundnut was sold into European markets, which is very difficult to achieve for SSA farmers due to rigid aflatoxin regulations (Ramsay et al. 2019). The aflatoxin testing was performed in-situ, contrary to the predominant practice of doing so in laboratories. The in-situ testing provides farmers, extension officers, buyers, and agro-dealers the opportunity to participate in the process and witness the results. Demonstrating to farmers that their crops contain safe or unsafe aflatoxin levels increases the potential for adoption of management strategies. It is difficult to convince farmers of the importance of aflatoxin management when testing is conducted in a far-away laboratory. The in-situ testing has increased confidence in biocontrol as part of an aflatoxin management system. It most importantly allows farmers to rapidly know if they can sell their crops in premium markets to obtain higher income. Following segregation of groundnut lots with low aflatoxin content as revealed by the in-situ testing, some aflatoxin-conscious buyers and farmers submitted samples to an approved laboratory. Those buyers and farmers randomly collected 25 
to $70 \mathrm{~kg}$ of kernels, milled them using a hammer mill, and thereafter submitted a homogenized $25 \mathrm{~g}$ subsample for analyses.

We have argued that use of native atoxigenic genotypes as active ingredient fungi of biocontrol formulations provides better chances to reduce crop aflatoxin content compared with the use of exotic fungi (Agbetiameh et al. 2019, 2020; Bandyopadhyay et al. 2016; Ortega-Beltran and Bandyopadhyay 2019; Senghor et al. 2020). Native fungi are locally adapted to environmental conditions and have higher chances to outcompete fungi residing in treated fields (Mehl et al. 2012; Probst et al. 2011). Therefore, using exotic atoxigenic fungi in biocontrol programs may not result in reductions to aflatoxin-compliant levels because of poor active ingredient adaptation to the target region. Besides, the use of atoxigenic exotic fungi may not be accepted by biopesticide regulatory authorities in most countries due to the perceived risk of environmental impact. We continue supporting the principle that use of atoxigenic fungi as biocontrol agents should be pursued only when there is evidence that these fungi are native to a target area in order to increase aflatoxin reductions and to alleviate any concerns related to the introduction of exotic organisms. There are many atoxigenic germplasm in all regions where aflatoxinproducing fungi thrive (Mehl et al. 2012).

Here we document for the first time the use in two countries of the same aflatoxin biocontrol product, Aflasafe SN01, composed of active ingredient fungi native to both nations, Senegal and The Gambia. Manufacturing and distribution responsibilities of Aflasafe SN01 have been licensed to BAMTAARE SA, a private company in Senegal (Schreurs et al. 2019; Senghor et al. 2020). BAMTAARE's manufacturing facility, now operational in Kaolack, Senegal, produced the biocontrol product for use during the 2019 and 2020 cropping seasons in both Senegal and The Gambia. The current results suggest that large-scale use of Aflasafe SNO1 as a centerpiece of an integrated aflatoxin management system will provide substantial benefits to human health, food security, income, and trade sectors in multiple nations in West Africa, which suffer from recurrent aflatoxin contamination events.

\section{Acknowledgments}

Special thanks to the maize and groundnut farmers in The Gambia for willingly allowing the trials to be conducted in their fields and participating in the current study. We thank Antony Carvalho and Mustapha Coley from NFSPMC, for supporting the field trials.

\section{Literature Cited}

Agbetiameh, D., Ortega-Beltran, A., Awuah, R. T., Atehnkeng, J., Cotty, P. J., and Bandyopadhyay, R. 2018. Prevalence of aflatoxin contamination in maize and groundnut in Ghana: population structure, distribution, and toxigenicity of the causal agents. Plant Dis. 102:764-772.

Agbetiameh, D., Ortega-Beltran, A., Awuah, R. T., Atehnkeng, J., Elzein, A., Cotty, P. J., and Bandyopadhyay, R. 2020. Field efficacy of two atoxigenic biocontrol products for mitigation of aflatoxin contamination in maize and groundnut in Ghana. Biol. Control 150:104351.

Agbetiameh, D., Ortega-Beltran, A., Awuah, R. T., Atehnkeng, J., Islam, M.-S., Callicott, K. A., Cotty, P. J., and Bandyopadhyay, R. 2019. Potential of atoxigenic Aspergillus flavus vegetative compatibility groups associated with maize and groundnut in Ghana as biocontrol agents for aflatoxin management. Front. Microbiol. 10:2069.

Amaike, S., and Keller, N. P. 2011. Aspergillus flavus. Annu. Rev. Phytopathol. 49:107-133.

Aoun, M., Stafstrom, W., Priest, P., Fuchs, J., Windham, G. L., Williams, P., and Nelson, R. J. 2020. Low-cost grain sorting technologies to reduce mycotoxin contamination in maize and groundnut. Food Control 118:107363.

Atehnkeng, J., Donner, M., Ojiambo, P. S., Ikotun, B., Augusto, J., Cotty, P. J., and Bandyopadhyay, R. 2016. Environmental distribution and genetic diversity of vegetative compatibility groups determine biocontrol strategies to mitigate aflatoxin contamination of maize by Aspergillus flavus. Microb. Biotechnol. 9:75-88.

Atehnkeng, J., Ojiambo, P. S., Cotty, P. J., and Bandyopadhyay, R. 2014. Field efficacy of a mixture of atoxigenic Aspergillus flavus Link: FR vegetative compatibility groups in preventing aflatoxin contamination in maize (Zea mays L.). Biol. Control 72:62-70.

Atehnkeng, J., Ojiambo, P. S., Donner, M., Ikotun, B., Sikora, R. A., Cotty, P. J., and Bandyopadhyay, R. 2008. Distribution and toxigenicity of Aspergillus species isolated from maize kernels from three agro-ecological zones in Nigeria. Int. J. Food Microbiol. 122:74-84.
Ayalew, A., Kimanya, M., Matumba, L., Bandyopadhyay, R., Menkir, A., and Cotty, P. J. 2017. Controlling aflatoxins in maize in Africa: strategies, challenges and opportunities for improvement. Pages 1-24 in: Achieving Sustainable Cultivation of Maize. Volume 2: Cultivation Techniques, Pest and Disease Control. D. Watson, ed. Burleigh Dodds Science Publishing Limited, Cambridge, UK.

Bandyopadhyay, R., Atehnkeng, J., Ortega-Beltran, A., Akande, A., Falade, T. D. O., and Cotty, P. J. 2019. "Ground-truthing" efficacy of biological control for aflatoxin mitigation in farmers' fields in Nigeria: from field trials to commercial usage, a 10-year study. Front. Microbiol. 10:2528.

Bandyopadhyay, R., Ortega-Beltran, A., Akande, A., Mutegi, C., Atehnkeng, J., Kaptoge, L., Senghor, L. A., Adhikari, B. N., and Cotty, P. J. 2016. Biological control of aflatoxins in Africa: current status and potential challenges in the face of climate change. World Mycotoxin J. 9:771-789.

Bayman, P., and Cotty, P. J. 1991. Vegetative compatibility and genetic diversity in the Aspergillus flavus population of a single field. Can. J. Bot. 69:1707-1711.

Bayman, P., and Cotty, P. J. 1993. Genetic diversity in Aspergillus flavus association with aflatoxin production and morphology. Can. J. Bot. 71:23-31.

Bhandari, K. B., Longing, S. D., and West, C. P. 2020. Soil microbial communities in corn fields treated with atoxigenic Aspergillus flavus. Soil Syst. 4:35.

Bock, C. H., Mackey, B., and Cotty, P. J. 2004. Population dynamics of Aspergillus flavus in the air of an intensively cultivated region of south-west Arizona. Plant Pathol. 53:422-433.

Campbell, B. C., Molyneux, R. J., and Schatzki, T. F. 2003. Current research on reducing pre- and post-harvest aflatoxin contamination of U.S. almond, pistachio, and walnut. J. Toxicol. Toxin Rev. 22:225-266.

Castelino, J. M., Dominguez-Salas, P., Routledge, M. N., Prentice, A. M., Moore, S. E., Hennig, B. J., Wild, C. P., and Gong, Y. Y. 2014. Seasonal and gestation stage associated differences in aflatoxin exposure in pregnant Gambian women. Trop. Med. Int. Health 19:348-354.

Chang, P. K., Abbas, H. K., Weaver, M. A., Ehrlich, K. C., Scharfenstein, L. L., and Cotty, P. J. 2012. Identification of genetic defects in the atoxigenic biocontrol strain Aspergillus flavus K49 reveals the presence of a competitive recombinant group in field populations. Int. J. Food Microbiol. 154:192-196.

Cotty, P. J. 1989. Virulence and cultural characteristics of two Aspergillus flavus strains pathogenic on cotton. Phytopathology 79:808-814.

Cotty, P. J. 1994. Comparison of four media for the isolation of Aspergillus flavus group fungi. Mycopathologia 125:157-162.

Cotty, P. J. 1997. Aflatoxin-producing potential of communities of Aspergillus section Flavi from cotton producing areas in the United States. Mycol. Res. 101:698-704

Cotty, P. J. 2006. Biocompetitive exclusion of toxigenic fungi. Pages 179-197 in: The Mycotoxin Factbook. D. Barug, D. Bhatnagar, H. P. van Egdmond, J. W. van der Kamp, W. A. van Osenbruggen, and A. Visconti, eds. Academic Publishers, Wageningen, The Netherlands.

Cotty, P. J., Antilla, L., and Wakelyn, P. J. 2007. Competitive exclusion of aflatoxin producers: Farmer-driven research and development. Pages 241-253 in: Biological Control: A Global Perspective. C. Vincent, M. S. Goettel, and G. Lazarovits, eds. CAB International, Oxfordshire, UK.

Cotty, P. J., and Cardwell, K. F. 1999. Divergence of West African and North American communities of Aspergillus section Flavi. Appl. Environ. Microbiol. 65:2264-2266.

Cotty, P. J., Probst, C., and Jaime-Garcia, R. 2008. Etiology and management of aflatoxin contamination. Pages 287-299 in: Mycotoxins: detection methods, management, public health and agricultural trade. J. F. Leslie, R. Bandyopadhyay, and A. Visconti, eds. CAB International, Oxfordshire, UK.

Diedhiou, P. M., Bandyopadhyay, R., Atehnkeng, J., and Ojiambo, P. S. 2011. Aspergillus colonization and aflatoxin contamination of maize and sesame kernels in two agro-ecological zones in Senegal. J. Phytopathol. 159: 268-275.

Donner, M., Atehnkeng, J., Sikora, R. A., Bandyopadhyay, R., and Cotty, P. J 2010. Molecular characterization of atoxigenic strains for biological control of aflatoxins in Nigeria. Food Addit. Contam. Part A Chem. Anal. Control Expo. Risk Assess. 27:576-590.

Dorner, J. W. 2004. Biological control of aflatoxin contamination of crops. J. Toxicol. Toxin Rev. 23:425-450.

Dorner, J. W. 2009. Development of biocontrol technology to manage aflatoxin contamination in peanuts. Peanut Sci. 36:60-67.

Dorner, J. W., and Cole, R. J. 1993. Variability among peanut subsamples prepared for aflatoxin analysis with four mills. J. AOAC Int. 76:983-987.

Dorner, J. W., and Cole, R. J. 2002. Effect of application of nontoxigenic strains of Aspergillus flavus and A. parasiticus on subsequent aflatoxin contamination of peanuts in storage. J. Stored Prod. Res. 38:329-339.

Doster, M. A., Cotty, P. J., and Michailides, T. J. 2014. Evaluation of the atoxigenic Aspergillus flavus strain AF36 in pistachio orchards. Plant Dis. 98:948-956.

Drott, M. T., Fessler, L. M., and Milgroom, M. G. 2019. Population subdivision and the frequency of aflatoxigenic isolates in Aspergillus flavus in the United States. Phytopathology 109:878-886.

Ehrlich, K. C., Moore, G. G., Mellon, J. E., and Bhatnagar, D. 2015. Challenges facing the biological control strategy for eliminating aflatoxin contamination. World Mycotoxin J. 8:225-233. 
Ezekiel, C. N., Atehnkeng, J., Odebode, A., and Bandyopadhyay, R. 2014. Distribution of aflatoxigenic Aspergillus section Flavi in commercial poultry feed in Nigeria. Int. J. Food Microbiol. 189:18-25.

Ezekiel, C. N., Ortega-Beltran, A., Oyedeji, E. O., Atehnkeng, J., Kössler, P., Tairu, F., Hoeschle-Zeledon, I., Karlovsky, P., Cotty, P. J., and Bandyopadhyay, R. 2019. Aflatoxin in chili peppers in Nigeria: extent of contamination and control using atoxigenic Aspergillus flavus genotypes as biocontrol agents. Toxins (Basel) 11:429.

Frisvad, J. C., Hubka, V., Ezekiel, C. N., Hong, S.-B., Novakova, A., Chen, A. J., Arzanlou, M., Larsen, T. O., Sklenář, F., Mahakarnchanakul, W., and Samson, R. A. 2019. Taxonomy of Aspergillus section Flavi and their production of aflatoxins, ochratoxins and other mycotoxins. Stud. Mycol. 93:1-63.

Gressel, J., and Polturak, G. 2018. Suppressing aflatoxin biosynthesis is not a breakthrough if not useful. Pest Manag. Sci. 74:17-21.

Groopman, J. D., Hall, A. J., Whittle, H., Hudson, G. J., Wogan, G. N., Montesano, R., and Wild, C. P. 1992. Molecular dosimetry of aflatoxin-N7-guanine in human urine obtained in The Gambia, West Africa. Cancer Epidemiol. Biomar. 1:221-227.

Grubisha, L. C., and Cotty, P. J. 2010. Genetic isolation among sympatric vegetative compatibility groups of the aflatoxin-producing fungus Aspergillus flavus. Mol. Ecol. 19:269-280.

Grubisha, L. C., and Cotty, P. J. 2015. Genetic analysis of the Aspergillus flavus vegetative compatibility group to which a biological control agent that limits aflatoxin contamination in U.S. crops belongs. Appl. Environ. Microbiol. 81: 5889-5899.

Hanlon, P. R., Bandyopadhyay, R., and Brorby, G. P. 2019. Evaluating the applicability of a risk-based approach (decision tree) to mycotoxins mitigation. Food Prot. Trends 39:406-416.

Hell, K., Cardwell, K. F., and Poehling, H. M. 2003. Relationship between management practices, fungal infection and aflatoxin for stored maize in Benin. J. Phytopathol. 151:690-698.

Horn, B. W. 2003. Ecology and population biology of aflatoxigenic fungi in soil. J. Toxicol. Toxin Rev. 22:351-379.

Hudson, G. J., Wild, C. P., Zarba, A., and Groopman, J. D. 1992. Aflatoxins isolated by immunoaffinity chromatography from foods consumed in The Gambia, West Africa. Nat. Toxins 1:100-105.

ICRISAT. 1990. Summary Proceedings of the First ICRISAT Regional Groundnut Meeting for West Africa, 13-16 Sep 1988, Niamey, Niger. International Crops Research Institute for the Semi-Arid Tropics, Patancheru, India.

Islam, M. S., Callicott, K. A., Mutegi, C., Bandyopadhyay, R., and Cotty, P. J. 2018. Aspergillus flavus resident in Kenya: high genetic diversity in an ancient population primarily shaped by clonal reproduction and mutationdriven evolution. Fungal Ecol. 35:20-33.

Jallow, E. A., Jarju, O. M., Mendy, B., Dumevi, R., Mendy, W. F., and Cham, K. 2019. The trend of aflatoxin contamination levels in groundnuts from 20082018 in The Gambia. LJRS 19:1-8.

JECFA. 2018. Safety evaluation of certain contaminants in food: prepared by the eighty-third meeting of the Joint FAO/WHO Expert Committee on Food Additives (JECFA). WHO Food A. World Health Organization and Food and Agriculture Organization of the United Nations, Geneva, Switzerland.

Kachapulula, P. W., Akello, J., Bandyopadhyay, R., and Cotty, P. J. 2017a. Aflatoxin contamination of groundnut and maize in Zambia: observed and potential concentrations. J. Appl. Microbiol. 122:1471-1482.

Kachapulula, P. W., Akello, J., Bandyopadhyay, R., and Cotty, P. J. 2017 b. Aspergillus section Flavi community structure in Zambia influences aflatoxin contamination of maize and groundnut. Int. J. Food Microbiol. 261:49-56.

Kinyungu, S., Isakeit, T., Ojiambo, P. S., and Woloshuk, C. P. 2019. Spread of Aspergillus flavus and aflatoxin accumulation in postharvested maize treated with biocontrol products. J. Stored Prod. Res. 84:101519.

Kirk, G. D., Bah, E., and Montesano, R. 2006. Molecular epidemiology of human liver cancer: insights into etiology, pathogenesis and prevention from The Gambia, West Africa. Carcinogenesis 27:2070-2082.

Klich, M. A. 2007. Aspergillus flavus: the major producer of aflatoxin. Mol. Plant Pathol. 8:713-722.

Klich, M. A., and Pitt, J. I. 1988. Differentiation of Aspergillus flavus from A. parasiticus and other closely related species. Trans. Br. Mycol. Soc. 91:99-108.

Köhl, J., Booij, K., Kolnaar, R., and Ravensberg, W. J. 2019. Ecological arguments to reconsider data requirements regarding the environmental fate of microbial biocontrol agents in the registration procedure in the European Union. BioControl 64:469-487.

Kuniholm, M. H., Lesi, O. A., Mendy, M., Akano, A. O., Sam, O., Hall, A. J., Whittle, H., Bah, E., Goedert, J. J., Hainaut, P., and Kirk, G. D. 2008. Aflatoxin exposure and viral hepatitis in the etiology of liver cirrhosis in The Gambia, West Africa. Environ. Health Perspect. 116:1553-1557.

Leslie, J. F. 1993. Fungal vegetative compatibility. Annu. Rev. Phytopathol. 31: 127-150.

Lillehoj, E. B., Kwolek, W. F., Horner, E. S., Widstrom, N. W., Josephson, L. N., Franz, A. O., and Catalano, E. A. 1980. Aflatoxin contamination of preharvest corn: role of Aspergillus flavus inoculum and insect damage. Cereal Chem. 57: 255-257.

Mahuku, G., Nzioki, H. S., Mutegi, C., Kanampiu, F., Narrod, C., and Makumbi, D. 2019. Pre-harvest management is a critical practice for minimizing aflatoxin contamination of maize. Food Control 96:219-226.
Matumba, L., Van Poucke, C., Monjerezi, M., Njumbe Ediage, E. N., and De Saeger, S. 2015. Concentrating aflatoxins on the domestic market through groundnut export: a focus on Malawian groundnut value and supply chain. Food Control 51:236-239.

Matumba, L., Van Poucke, C., Njumbe Ediage, E. N., and De Saeger, S. 2017 Keeping mycotoxins away from the food: does the existence of regulations have any impact in Africa? Crit. Rev. Food Sci. Nutr. 57:1584-1592.

Mehl, H. L., Jaime, R., Callicott, K. A., Probst, C., Garber, N. P., Ortega-Beltran, A., Grubisha, L. C., and Cotty, P. J. 2012. Aspergillus flavus diversity on crops and in the environment can be exploited to reduce aflatoxin exposure and improve health. Ann. N. Y. Acad. Sci. 1273:7-17.

Moral, J., Garcia-Lopez, M. T., Camiletti, B. X., Jaime, R., Michailides, T. J., Bandyopadhyay, R., and Ortega-Beltran, A. 2020. Present status and perspective on the future use of aflatoxin biocontrol products. Agronomy (Basel) 10:491

Nishimwe, K., Bowers, E., Ayabagabo, J. de D., Habimana, R., Mutiga, S., and Maier, D. 2019. Assessment of aflatoxin and fumonisin contamination and associated risk factors in feed and feed ingredients in Rwanda. Toxins (Basel) 11:270

Ortega-Beltran, A., and Bandyopadhyay, R. 2019. Comments on "Trial summary on the comparison of various non-aflatoxigenic strains of Aspergillus flavus on mycotoxin levels and yield in maize" by M.S. Molo, et al. Agron. J. 111:942946 (2019). Agron. J. 111:2625-2631.

Ortega-Beltran, A., Callicott, K. A., and Cotty, P. J. 2020. Founder events influence structures of Aspergillus flavus populations. Environ. Microbiol. 22:3522-3534

Ortega-Beltran, A., and Cotty, P. J. 2018. Frequent shifts in Aspergillus flavus populations associated with maize production in Sonora, Mexico. Phytopathology 108:412-420.

Ortega-Beltran, A., Grubisha, L. C., Callicott, K. A., and Cotty, P. J. 2016. The vegetative compatibility group to which the US biocontrol agent Aspergillus flavus AF36 belongs is also endemic to Mexico. J. Appl. Microbiol. 120: 986-998.

Ortega-Beltran, A., Moral, J., Picot, A., Puckett, R. D., Cotty, P. J., and Michailides, T. J. 2019. Atoxigenic Aspergillus flavus isolates endemic to almond, fig, and pistachio orchards in California with potential to reduce aflatoxin contamination in these crops. Plant Dis. 103:905-912.

PACA. 2019. Strengthening aflatoxin control in The Gambia: policy recommendations. Based on findings of the country-led situation analysis and action planning (CSAAP) conducted from 2015 to 2017 by Partnership for Aflatoxin Control in Africa (PACA). Available at: https://www.aflatoxinpartnership.org/wpcontent/uploads/2020/06/Gambia_Aflatoxin_Control_MAY15.pdf. Accessed 14 November 2020.

Probst, C., Bandyopadhyay, R., and Cotty, P. J. 2014. Diversity of aflatoxinproducing fungi and their impact on food safety in sub-Saharan Africa. Int. J. Food Microbiol. 174:113-122.

Probst, C., Bandyopadhyay, R., Price, L. E., and Cotty, P. J. 2011. Identification of atoxigenic Aspergillus flavus isolates to reduce aflatoxin contamination of maize in Kenya. Plant Dis. 95:212-218.

Probst, C., and Cotty, P. J. 2012. Relationships between in vivo and in vitro aflatoxin production: reliable prediction of fungal ability to contaminate maize with aflatoxins. Fungal Biol. 116:503-510.

Ramsay, D., Kovacevic, M., Gonzalez, V., and Diallo, A. 2019. Detoxifying crops in The Gambia, from the ground up. Trade for Development News. https:// trade4devnews.enhancedif.org/en/impact-story/detoxifying-crops-gambiaground/ accessed 1 June 2020.

RASFF. 2019. RASFF - The Rapid Alert System for Food and Feed — 2018 annual report. https://doi.org/10.2875/914558

Schreurs, F., Bandyopadhyay, R., Kooyman, C., Ortega-Beltran, A., Akande, A., Konlambigue, M., and van den Bosch, N. 2019. Commercial products promoting plant health in African agriculture. Pages 345-363 in: Critical issues in plant health: 50 years of research in African agriculture. P. Neuenschwander and M. Tamò, eds. Burleigh Dodds Science Publishing, Cambridge, UK

Seetha, A., Munthali, W., Msere, H. W., Swai, E., Muzanila, Y., Sichone, E., Tsusaka, T. W., Rathore, A., and Okori, P. 2017. Occurrence of aflatoxins and its management in diverse cropping systems of central Tanzania. Mycotoxin Res. 33:323-331.

Senghor, L. A., Ortega-Beltran, A., Atehnkeng, J., Callicott, K. A., Cotty, P. J., and Bandyopadhyay, R. 2020. The atoxigenic biocontrol product Aflasafe SN01 is a valuable tool to mitigate aflatoxin contamination of both maize and groundnut cultivated in Senegal. Plant Dis. 104:510-520.

Shephard, G. S. 2008. Risk assessment of aflatoxins in food in Africa. Food Addit Contam. 25:1246-1256.

Singh, P., and Cotty, P. J. 2019. Characterization of Aspergilli from dried red chilies (Capsicum spp.): insights into the etiology of aflatoxin contamination. Int. J. Food Microbiol. 289:145-153.

Turner, P. C., Collinson, A. C., Cheung, Y. B., Gong, Y., Hall, A. J., Prentice, A. M., and Wild, C. P. 2007. Aflatoxin exposure in utero causes growth faltering in Gambian infants. Int. J. Epidemiol. 36:1119-1125.

Turner, P. C., Mendy, M., Whittle, H., Fortuin, M., Hall, A. J., and Wild, C. P. 2000. Hepatitis B infection and aflatoxin biomarker levels in Gambian children. Trop. Med. Int. Health 5:837-841. 
Turner, P. C., Moore, S. E., Hall, A. J., Prentice, A. M., and Wild, C. P. 2003. Modification of immune function through exposure to dietary aflatoxin in Gambian children. Environ. Health Perspect. 111:217-220.

Udomkun, P., Wiredu, A., Nagle, M., Bandyopadhyay, R., Müller, J., and Vanlauwe, B. 2017a. Mycotoxins in sub-Saharan Africa: present situation, socio-economic impact, awareness, and outlook. Food Control 72:110-122.

Udomkun, P., Wiredu, A., Nagle, M., Müller, J., Vanlauwe, B., and Bandyopadhyay, R. 2017b. Innovative technologies to manage aflatoxins in foods and feeds and the profitability of application - A review. Food Control $76: 127-138$

Villers, P. 2014. Aflatoxins and safe storage. Front. Microbiol. 5:158.

Waliyar, F., Kumar, P. L., Traoré, A., Ntare, B. R., Diarra, B., and Kodio, O. 2008. Pre- and postharvest management of aflatoxin contamination in peanuts. Pages 209-218 in: Mycotoxins: detection methods, management, public health and agricultural trade. J. F. Leslie, R. Bandyopadhyay, and A. Visconti, eds. CAB International, Oxfordshire, UK.
Waliyar, F., Osiru, M., Ntare, B. R., Kumar, K. V. K., Sudini, H., Traore, A., and Diarra, B. 2015. Post-harvest management of aflatoxin contamination in groundnut. World Mycotoxin J. 8:245-252.

Wild, C. P., Hudson, G. J., Sabbioni, G., Chapot, B., Hall, A. J., Wogan, G. N., Whittle, H., Montesano, R., and Groopman, J. D. 1992. Dietary intake of aflatoxins and the level of albumin-bound aflatoxin in peripheral blood in The Gambia, West Africa. Cancer Epidemiol. Biomar. 1:229-234.

Wu, F. 2015. Global impacts of aflatoxin in maize: trade and human health. World Mycotoxin J. 8:137-142.

Xu, Y., Doel, A., Watson, S., Routledge, M. N., Elliott, C. E., Moore, S. E., and Gong, Y. Y. 2017. Study of an educational hand sorting intervention for reducing aflatoxin $B_{1}$ in groundnuts in rural Gambia. J. Food Prot. 80:44-49.

Zarba, A., Wild, C. P., Hall, A. J., Montesano, R., Hudson, G. J., and Groopman, J. D. 1992. Aflatoxin M1 in human breast milk from The Gambia, West Africa, quantified by combined monoclonal antibody immunoaffinity chromatography and HPLC. Carcinogenesis 13:891-894. 